\title{
Flexible freestanding all-MXene hybrid films with enhanced capacitive performance for powering flex sensor
}

Received 00th January 20xx, Accepted 00th January 20xx DOI: $10.1039 / \times 0 \times x 00000 x$

\author{
Zhemin Li, ${ }^{a}$ Yohan Dall'Agnese, ${ }^{\text {b }}$ Jin Guo, ${ }^{a}$ Haifu Huang, ${ }^{a}$ Xianqing Liang ${ }^{\text {a }}$ and Shuaikai Xu*a
}

Stacking different two-dimensional (2D) nanomaterials into composite structures opens an opportunity to fabricate electrodes combining the advantages of the individual nanomaterial. Here, different types of MXene nanosheets are combined to create flexible all-MXene hybrid films with high gravimetric capacitance and excellent rate performance for flexible supercapacitors. $\mathrm{Ti}_{3} \mathrm{C}_{2} \mathrm{~T}_{\mathrm{x}}$ nanosheets are introduced in-between $\mathrm{Nb}_{2} \mathrm{CT}_{\mathrm{x}}$ layers, leading to a significantly increased interlayer spacing. The self-restacking of both types of MXenes nanosheets is effectively impeded, accelerating the diffusion of electrolyte ions and enabling more accessible $2 \mathrm{D}$ nanochannels. The freestanding $\mathrm{Ti}_{3} \mathrm{C}_{2} \mathrm{~T}_{\mathrm{x}} / \mathrm{Nb}_{2} \mathrm{CT}_{\mathrm{x}}$ films delivers a high gravimetric capacitance of $370 \mathrm{~F} \mathrm{~g}^{-1}$ at a scan rate of $2 \mathrm{mV} \mathrm{s}^{-1}$, good rate performance with $56.1 \%$ capacitance retention at $200 \mathrm{mV} \mathrm{s}^{-1}$ and long cycle life. Furthermore, the energy density of the assembled all-solid-state symmetric supercapacitor can reach up to $5.5 \mathrm{mWh} \mathrm{g}^{-1}$ at power density of $141.4 \mathrm{~mW} \mathrm{~g}^{-1}$. Serving as stable power source unit, the all-solid-state supercapacitor was also integrated with a flex sensor to fabricated self-powered device. The route to fabricate $\mathrm{Ti}_{3} \mathrm{C}_{2} \mathrm{~T}_{\mathrm{x}} / \mathrm{Nb}_{2} \mathrm{CT}_{\mathrm{x}}$ hybrid films with enhanced electrochemical performance is also applicable for other MXenes, promoting the applications of MXenes for flexible supercapacitors and integrated electronic devices.

\section{Introduction}

Flexible supercapacitors are playing an increasingly important role in energy storage due to their viability for flexible intelligent wearable electronic devices, which requires irregular power supply at different discharging rates. ${ }^{1-3}$ Two-dimensional (2D) nanomaterials have gradually become potential electrode materials for flexible supercapacitors due to their atomic thickness and electrochemical active surface, especially they allow the development of binder-free flexible electrodes with improved capacitance. ${ }^{4}$ 2D materials can provide slit-shaped ion diffusion channels that enable fast movement of electrolyte ions into the electrode bulk. ${ }^{4}$

In recent years, a new family of two-dimensional material called MXenes has been discovered, which are transition metal carbides and nitrides with a general formula of $M_{n+1} X_{n} T_{x}$, where $M$ is an early transition metal, $X$ represents $C$ and/or $N, T_{x}$ denotes surface functional groups, and $n=1,2$, or $3 . .^{5-7}$ They can be generally obtained by selectively etching out the $A$ atomic layers of corresponding MAX phase precursors. ${ }^{8}$ The advantages of MXenes include to their metallic conductivity and hydrophilic surface. MXenes have proven to be promising candidates for supercapacitors with high specific capacitance under high charging rate, outperforming most previously reported materials. ${ }^{1,9-13}$ Among all MXenes, $\mathrm{Ti}_{3} \mathrm{C}_{2} \mathrm{~T}_{\mathrm{x}}$ is the most widely studied because of its well established preparation

a. Guangxi Colleges and Universities Key Laboratory of Novel Energy Materials and Related Technology, Guangxi Novel Battery Materials Research Center of Engineering Technology, Center on Nanoenergy Research, College of Physics Science and Technology, Guangxi University, Nanning 530004, P. R. China.

b. Institute for Materials Discovery, University College London, London WC1E TJE, United Kingdom.

* Corresponding author. E-mail: skxu@gxu.edu.cn. method and good conductivity. ${ }^{6,14-18} \mathrm{M}$. Ghidiu et al. reported a method of producing $\mathrm{Ti}_{3} \mathrm{C}_{2} \mathrm{~T}_{x} \mathrm{MXene}$ using a solution of $\mathrm{LiF} / \mathrm{HCl}$, and the resulting additive-free $\mathrm{Ti}_{3} \mathrm{C}_{2} \mathrm{~T}_{\mathrm{x}}$ films have volumetric capacitances of up to $900 \mathrm{~F} \mathrm{~cm}^{-3}$ in sulfuric acid with excellent cyclability and rate performances. ${ }^{19}$ As with other two-dimensional materials, the restacking of the MXene nanosheets impedes the accessibility to electrolyte ions, hindering the full utilization of the whole electrode. ${ }^{7}$ Introducing interlayer spacers between nanosheets is an effective and straightforward strategy to improve the electrochemical performance of MXenes. ${ }^{20}$ For instance, carbon nanotubes, graphene and activated carbon have been combined with $\mathrm{Ti}_{3} \mathrm{C}_{2} \mathrm{~T}_{\mathrm{x}}$ to fabricate flexible hybrid film electrodes with significantly improved electrochemical performance. ${ }^{21-28}$

Besides $\mathrm{Ti}_{3} \mathrm{C}_{2} T_{x}$, the studies of MXenes with a formula of $\mathrm{M}_{2} \mathrm{X} T_{x}$, for example $\mathrm{Nb}_{2} \mathrm{CT}_{x}$, are rarely reported for aqueous supercapacitors. $\mathrm{M}_{2} \mathrm{XT}_{\mathrm{x}} \mathrm{MXenes}$ were generally used as anode materials for alkali metal-ion batteries or non-aqueous hybrid energy storage devices. ${ }^{29-}$ 33 However, $\mathrm{M}_{2} \mathrm{XT}_{\mathrm{x}}$ MXenes may achieve higher specific capacitance than $\mathrm{Ti}_{3} \mathrm{C}_{2} \mathrm{~T}_{\mathrm{x}} .{ }^{34}, 35$ Theoretical calculation predicted $\mathrm{Nb}_{2} \mathrm{C}$ to possess superior gravimetric and areal capacitances than $\mathrm{Ti}_{3} \mathrm{C}_{2}$. In $\mathrm{Nb}_{2} \mathrm{C}$ MXene, $\mathrm{Nb}$ atomic layers surface of $\mathrm{Nb}_{2} \mathrm{C}$ can be fully utilized, enabling sufficient redox sites when acting as intercalation pseudocapacitive electrodes. In addition, the $\mathrm{Nb}$ element in $\mathrm{Nb}_{2} \mathrm{CT}_{x}$ possesses wider chemical valence than Ti element, providing higher electrochemical activity. However, higher reaction temperature and longer reaction time are often required to etch $\mathrm{Nb}_{2} \mathrm{AlC}$ MAX by concentrated $\mathrm{HF}$ solution, causing that prepared $\mathrm{Nb}_{2} \mathrm{CT}_{\mathrm{x}}$ MXene to have more lattice defects and a smaller nanosheet size. ${ }^{33,}{ }^{34}$ As a result, the electrical conductivity of $\mathrm{Nb}_{2} \mathrm{CT}_{\mathrm{x}}$ is relatively lower than $\mathrm{Ti}_{3} \mathrm{C}_{2} \mathrm{~T}_{x}$, which limits $\mathrm{Nb}_{2} \mathrm{CT}_{\mathrm{x}}$ potential application in high power electrochemical energy storage. 
To overcome the limitations of individual 2D nanomaterial, combining different 2D materials in hybrid electrodes by alternating stacking can be an effective strategy. ${ }^{36-39}$ Stacking different 2D materials into composite structures opens an opportunity to construct electrodes that would combine the advantages of the individual building blocks while eliminating the associated shortcomings. ${ }^{38}$ Analogously, combining $\mathrm{Nb}_{2} \mathrm{CT}_{\mathrm{x}} \mathrm{MXene}$ nanosheets with other 2D nanomaterials into composite structures could combine the advantages of the individual material, including high conductivity and high intercalation pseudocapacitance.$^{40}$ It has been reported that graphene, principally reduced graphene oxide ( $\mathrm{rGO}$ ), is a promising candidate to be assembled with MXene nanosheets into stacked 2D hybrid films. ${ }^{23,37}$ In our previous work, $\mathrm{rGO}$ was combined with $\mathrm{Ti}_{3} \mathrm{C}_{2} \mathrm{~T}_{\mathrm{x}}$ to prepare $\mathrm{rGO} / \mathrm{Ti}_{3} \mathrm{C}_{2} \mathrm{~T}_{\mathrm{x}}$ films for supercapacitors. ${ }^{26}$ However, the colloidal dispersion of graphene with hydrophobic surfaces in water is generally difficult to be achieved. In addition, the thermal reduction process to reduce graphene oxide is energyintensive and deteriorate the mechanical strength of the hybrid films. In contrast to graphene, $\mathrm{Ti}_{3} \mathrm{C}_{2} \mathrm{~T}_{\mathrm{x}}$ has high conductivity, hydrophilic surface and high intercalation pseudocapacitance. ${ }^{41}$ Therefore, it would be an appropriate selection to stack $\mathrm{Ti}_{3} \mathrm{C}_{2} \mathrm{~T}_{\mathrm{x}}$ with $\mathrm{Nb}_{2} \mathrm{CT}_{\mathrm{x}}$ nanosheets to fabricate flexible hybrid films with expected high capacitive performance. Moreover, the aqueous solution processing of hybrid suspension based on two-MXene nanosheets is favorable for the large-scalable preparation of MXene-based films.
In this work, we proposed the concept of all-MXenes hybrid films for the first time. We prepared $\mathrm{Nb}_{2} \mathrm{CT}_{\mathrm{x}} \mathrm{MXene}$ at a lower reaction temperature and a shorter reaction time than previous report. 9, 31 Few-layer $\mathrm{Nb}_{2} \mathrm{CT}_{\mathrm{x}}$ nanosheets are obtained through manually shaking the multi-layer $\mathrm{Nb}_{2} \mathrm{CT}_{\mathrm{x}}$ intercalated by tetramethylammonium hydroxide $(\mathrm{TMAOH})$. The simple vacuum filtration process is conducted to stack few-layer $\mathrm{Nb}_{2} \mathrm{CT}_{\mathrm{x}}$ and $\mathrm{Ti}_{3} \mathrm{C}_{2} \mathrm{~T}_{\mathrm{x}}$ nanosheets layer by layer and fabricate flexible $\mathrm{Ti}_{3} \mathrm{C}_{2} \mathrm{~T}_{\mathrm{x}} / \mathrm{Nb}_{2} \mathrm{CT}_{\mathrm{x}}$ hybrid films for ultrafast flexible supercapacitors. The resultant $\mathrm{Ti}_{3} \mathrm{C}_{2} \mathrm{~T}_{\mathrm{x}} / \mathrm{Nb}_{2} \mathrm{CT}_{\mathrm{x}}$ films efficiently alleviates the self-restacking of both $\mathrm{Ti}_{3} \mathrm{C}_{2} \mathrm{~T}_{\mathrm{x}}$ and $\mathrm{Nb}_{2} \mathrm{CT}_{x}$ nanosheets. In addition, the $\mathrm{Ti}_{3} \mathrm{C}_{2} \mathrm{~T}_{\mathrm{x}}$ nanosheets intercalated between $\mathrm{Nb}_{2} \mathrm{CT}_{\mathrm{x}}$ nanosheets can act as conductive network while increasing the interlayer spacing of $\mathrm{Nb}_{2} \mathrm{CT}_{\mathrm{x}}$, providing more accessible 2D nanochannels for electrolyte ions and ensuring highrate performance. As a result, the flexible $2 \mathrm{D}$ hybrid film delivers improved capacitance up to $370 \mathrm{~F} \mathrm{~g}^{-1}$ at $2 \mathrm{mV} \mathrm{s}^{-1}$ with $56.1 \%$ capacitance retention at $200 \mathrm{mV} \mathrm{s}^{-1}$, much higher than that of pure individual MXene films. Moreover, the assembled all-solid-state supercapacitor can yield an energy density of $5.7 \mathrm{mWh} \mathrm{g}^{-1}$ at power density of $171.5 \mathrm{~mW} \mathrm{~g}^{-1}$. The all-solid-state supercapacitor presents excellent cyclability with $94 \%$ capacitance retention after 10,000 cycles. The assembled all-solid-state supercapacitor was used to supply a flex sensor, proving its potential for practical application in integrated intelligent wearable electronic devices.

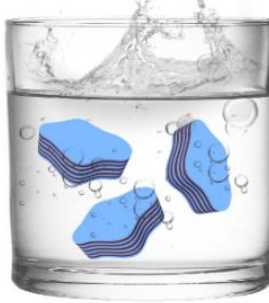

Etching Nb2AlC

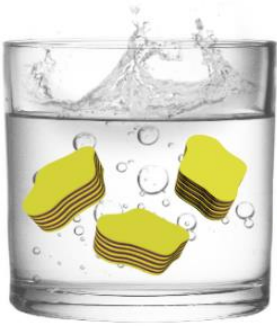

Etching $\mathrm{Ti}_{3} \mathrm{AIC} 2$

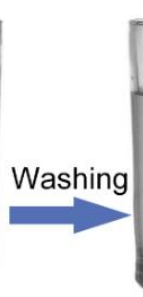

Multi-layer $\mathrm{Nb}_{2} \mathrm{CT} x$

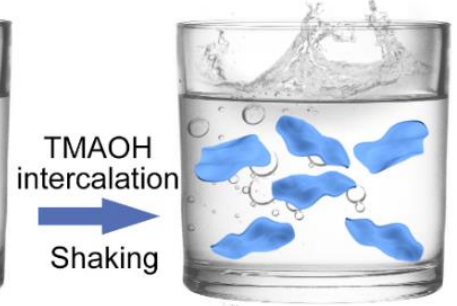

Few-layer $\mathrm{Nb}_{2} \mathrm{CTx}$

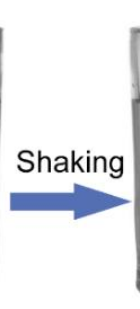

Few-layer $\mathrm{Ti}_{3} \mathrm{C}_{2} \mathrm{~T} \mathrm{x}$

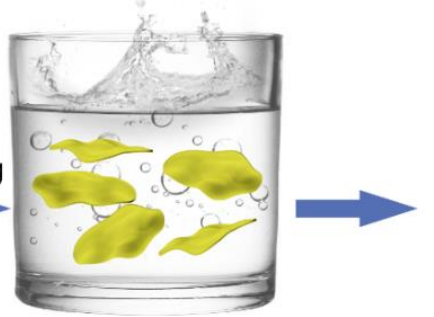

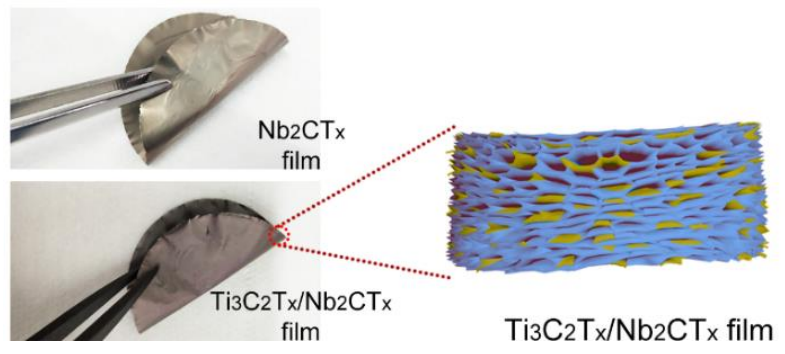

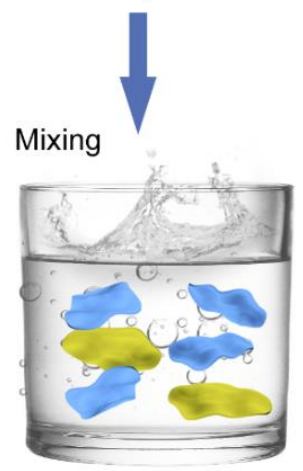

$\mathrm{Nb}_{2} \mathrm{CT}_{\mathrm{x}}+\mathrm{Ti}_{3} \mathrm{C}_{2} \mathrm{~T}_{\mathrm{x}}$

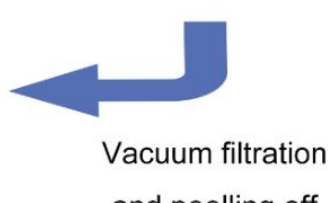

and peelling off

Fig. 1 The schematic of the fabrication process of flexible freestanding $T_{3} C_{2} T_{x} / N_{2} C_{x}$ hybrid films, and the optical photographs of the prepared films. 


\section{ARTICLE}

\section{Results and discussion}

Fig. 1 schematically illustrates the fabrication process of flexible hybrid $\mathrm{Ti}_{3} \mathrm{C}_{2} \mathrm{~T}_{\mathrm{x}} / \mathrm{Nb}_{2} \mathrm{CT}_{\mathrm{x}}$ film. Multi-layer $\mathrm{Nb}_{2} \mathrm{CT}_{\mathrm{x}}$ MXene was synthesized by HF etching of $\mathrm{Nb}_{2} \mathrm{AlC}$ MAX phase. Organic polar $\mathrm{TMAOH}$ molecules were intercalated between $\mathrm{Nb}_{2} \mathrm{CT}_{\mathrm{x}}$ layers to enlarge the interlayer spacing, followed by manual shaking to delaminate $\mathrm{Nb}_{2} \mathrm{CT}_{\mathrm{x}}$ into few-layer nanosheets. The few-layer $\mathrm{Ti}_{3} \mathrm{C}_{2} \mathrm{~T}_{\mathrm{x}}$ nanosheets were prepared according to the MILD method reported
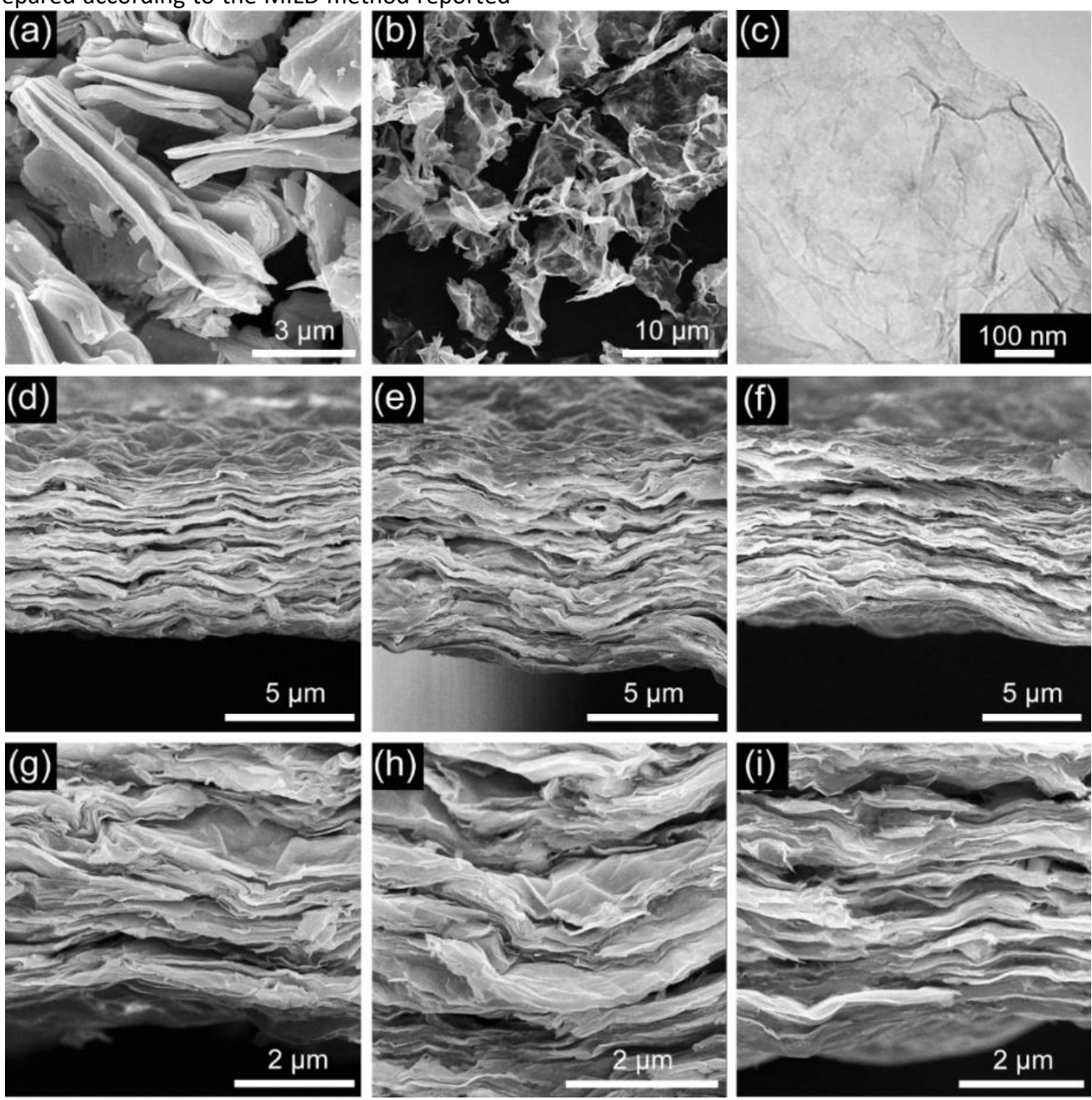

Fig. $2(a, b)$ The typical SEM images of HF-etched multi-layer $\mathrm{Nb}_{2} \mathrm{CT}_{\mathrm{x}} \mathrm{MXene}$ and delaminated few-layer $\mathrm{Nb}_{2} \mathrm{CT}_{\mathrm{x}}$ nanosheets, correspondingly. (c) TEM image of several $\mathrm{Nb}_{2} \mathrm{CT}_{x}$ nanosheets, showing large lateral sizes. (d-f) Cross-sectional SEM images of the $\mathrm{Ti}_{3} \mathrm{C}_{2} \mathrm{~T}_{x} / \mathrm{Nb}_{2} \mathrm{CT}_{x}$ hybrid films with $5 \mathrm{wt} \%, 10 \mathrm{wt} \%$ and $30 \mathrm{wt} \%$ of $\mathrm{Ti}_{3} \mathrm{C}_{2} \mathrm{~T}_{\mathrm{x}}$ in the hybrid films, correspondingly. (g-i) The high magnification SEM images of (d-f), correspondingly. 


\section{ARTICLE}

Scanning electron microscopy (SEM) and transmission electron microscopy (TEM) were employed to define the morphology and microstructure of the obtained nanomaterials. After etching $\mathrm{Al}$ atom layers out from $\mathrm{Nb}_{2} \mathrm{AlC}$, the obtained multi-layer $\mathrm{Nb}_{2} \mathrm{CT}_{x}$ present typical laminated structure as with the other MXenes, as shown in Fig. 2a. After delamination, the few-layer $\mathrm{Nb}_{2} \mathrm{CT}_{x}$ nanosheets present thin lamellar morphology (Fig. 2b). It can be further demonstrated from the TEM result shown in Fig. $2 c$ that the delaminated $\mathrm{Nb}_{2} \mathrm{CT}_{x}$ nanosheets are successfully prepared. Fig. S3a shows the SEM result of delaminated $\mathrm{Ti}_{3} \mathrm{C}_{2} \mathrm{~T}_{\mathrm{x}}$ nanosheets with larger lateral dimensions compared to $\mathrm{Nb}_{2} \mathrm{CT}_{x}$ nanosheets. $\mathrm{Ti}_{3} \mathrm{C}_{2} \mathrm{~T}_{x}$ nanosheets were observed using TEM (Fig. S3b), confirming that the $\mathrm{Ti}_{3} \mathrm{C}_{2} \mathrm{~T}_{x}$ nanosheets are indeed few layers thick. So that when combining $\mathrm{Nb}_{2} \mathrm{CT}_{\mathrm{x}}$ with $\mathrm{Ti}_{3} \mathrm{C}_{2} \mathrm{~T}_{\mathrm{x}}$ nanosheets, the introduction of $\mathrm{Ti}_{3} \mathrm{C}_{2} \mathrm{~T}_{\mathrm{x}}$ nanosheets can improve the electrical conductivity of the whole hybrid film. The cross-sectional SEM image of the pure $\mathrm{Nb}_{2} \mathrm{CT}_{x}$ film shown in Fig. S4a and b presents a well-aligned, layered structure. After combining with few-layer $\mathrm{Ti}_{3} \mathrm{C}_{2} \mathrm{~T}_{\mathrm{x}}$ nanosheets, the obtained $\mathrm{Ti}_{3} \mathrm{C}_{2} \mathrm{~T}_{\mathrm{x}} / \mathrm{Nb}_{2} \mathrm{CT}_{\mathrm{x}}$ hybrid films with different weight percent of $\mathrm{Ti}_{3} \mathrm{C}_{2} \mathrm{~T}_{x}$ all maintained the similar layered structure of pure $\mathrm{Nb}_{2} \mathrm{CT}_{x}$ film without any significant change, as shown in Fig. $2 \mathrm{~d}-\mathrm{i}$ and Fig. S4c, d. To clarify the homogeneous mixing degree of MXenes sheets in the films, EDS mapping images of the crosssectional views of all samples are added, as shown in Fig. S5. It can be seen that the $\mathrm{Ti}$ and $\mathrm{Nb}$ elements are evenly distributed in the hybrid films, indicating that $\mathrm{Ti}_{3} \mathrm{C}_{2} \mathrm{~T}_{\mathrm{x}}$ and $\mathrm{Nb}_{2} \mathrm{CT}_{\mathrm{x}}$ nanosheets are stacked homogeneously.

In order to analyze the material phases and the change of interlayer spacing between MXene nanosheets, X-diffraction (XRD) measurements were conducted on pure MXenes and hybrid films. As shown in Fig. S6a, after selective etching and delamination, the fabricated pure $\mathrm{Ti}_{3} \mathrm{C}_{2} \mathrm{~T}_{x}$ film presents a strong (002) diffraction peak at $6.7^{\circ}$, corresponding to an interlayer spacing of $1.31 \mathrm{~nm}$, which is almost consistent with previously reported results. ${ }^{10}$ As shown in Fig. $\mathrm{S} 6 \mathrm{~b}$, it can be seen that the (002) diffraction peak shifts from $12.8^{\circ}$ for $\mathrm{Nb}_{2} \mathrm{AlC} \mathrm{MAX}$ to $8.0^{\circ}$ for multi-layer $\mathrm{Nb}_{2} \mathrm{CT}_{\mathrm{x}}$ due to the complete etching of $\mathrm{Al}$ atom layers. The (002) diffraction peak of freestanding $\mathrm{Nb}_{2} \mathrm{CT}_{x}$ film further shifts to lower degree $\left(7.6^{\circ}\right)$ comparing to multilayer $\mathrm{Nb}_{2} \mathrm{CT}_{x}$, which can be attributed to the intercalation of water and TMAOH between $\mathrm{Nb}_{2} \mathrm{CT}_{x}$ nanosheets. When introducing $\mathrm{Ti}_{3} \mathrm{C}_{2} \mathrm{~T}_{x}$ nanosheets between $\mathrm{Nb}_{2} \mathrm{CT}_{\mathrm{x}}$ nanosheets, for example $10 \mathrm{wt} \%$ $\mathrm{Ti}_{3} \mathrm{C}_{2} \mathrm{~T}_{x}$, a new diffraction peak at $6.1^{\circ}$ appears for $10 \% \mathrm{~T}-\mathrm{N}$, as shown in Fig. 3a and $b$. The increasing interlayer spacing between $\mathrm{Nb}_{2} \mathrm{CT}_{x}$ nanosheets in $10 \% \mathrm{~T}-\mathrm{N}$ due to the interaction with $\mathrm{Ti}_{3} \mathrm{C}_{2} \mathrm{~T}_{\mathrm{x}}$ nanosheets should be responsible for this. On the other hand, the interlayer spacing between $\mathrm{Ti}_{3} \mathrm{C}_{2} \mathrm{~T}_{\mathrm{x}}$ nanosheets in $10 \% \mathrm{~T}-\mathrm{N}$ also significantly increased due to the compartmentation of $\mathrm{Nb}_{2} \mathrm{CT}_{x}$ layers, resulting in the shift of (002) peak below $5^{\circ}$. The XRD patterns of hybrid $\mathrm{Ti}_{3} \mathrm{C}_{2} \mathrm{~T}_{x} / \mathrm{Nb}_{2} \mathrm{CT}_{x}$ films with different content ratios are listed in Fig. $3 \mathrm{c}$ and $\mathrm{d}$. With the increase of $\mathrm{Ti}_{3} \mathrm{C}_{2} \mathrm{~T}_{\mathrm{x}}$ content from 5 to 30 $w t \%$, the intensity of the diffraction peak at $6.2^{\circ}$ gradually increases while the peak at $7.5^{\circ}$ decreases, indicating a stepwise decrease in the degree of stacking order of $\mathrm{Nb}_{2} \mathrm{CT}_{x}$ layers due to introducing of $\mathrm{Ti}_{3} \mathrm{C}_{2} \mathrm{~T}_{\mathrm{x}}$ nanosheets. However, when the $\mathrm{Ti}_{3} \mathrm{C}_{2} \mathrm{~T}_{\mathrm{x}}$ content increases to $50 \mathrm{wt} \%$, the diffraction peak at $6.2^{\circ}$ disappeared, which can be ascribed to the more intercalated $\mathrm{Ti}_{3} \mathrm{C}_{2} \mathrm{~T}_{\mathrm{x}}$ nanosheets between $\mathrm{Nb}_{2} \mathrm{CT}_{\mathrm{x}}$ layers. In addition, it's worth noting the diffraction peak at $8.7^{\circ}$, which could be attributed to the residual thick $\mathrm{Nb}_{2} \mathrm{CT}_{\mathrm{x}}$ layers after delamination. Considering the close molecular weights of $\mathrm{Nb}_{2} \mathrm{CT}_{\mathrm{x}}$ and $\mathrm{Ti}_{3} \mathrm{C}_{2} \mathrm{~T}_{\mathrm{x}}$, it can be estimated that $\mathrm{Ti}_{3} \mathrm{C}_{2} \mathrm{~T}_{\mathrm{x}}$ is excessive for effective embedding between $\mathrm{Nb}_{2} \mathrm{CT}_{x}$ layers in $50 \% \mathrm{~T}-\mathrm{N}$. The theoretical specific capacitance of $\mathrm{Nb}_{2} \mathrm{CT}_{x}$ is higher than that of $\mathrm{Ti}_{3} \mathrm{C}_{2} \mathrm{~T}_{\mathrm{x}}$ owing to the access to all transition metal layers and more abundant valence states of $\mathrm{Nb}$ atoms in $\mathrm{Nb}_{2} \mathrm{CT}_{\mathrm{x}} .{ }^{42} \mathrm{As}$ a result, with the increase of $\mathrm{Ti}_{3} \mathrm{C}_{2} \mathrm{~T}_{\mathrm{x}}$ content in the hybrid films from 5 to $30 \mathrm{wt} \%$, the electrical conductivity increases gradually and the electrochemical active surfaces of $\mathrm{Nb}_{2} \mathrm{CT}_{x}$ become more accessible to electrolyte ions, ensuring a high-power output during the fast charging and discharging processes. However, as for $50 \% \mathrm{~T}-\mathrm{N}$, its electrochemical active surfaces cannot be fully utilized due to the excess restacked $\mathrm{Ti}_{3} \mathrm{C}_{2} \mathrm{~T}_{\mathrm{x}}$ nanosheets, leading to possible reduced electrochemical performance.
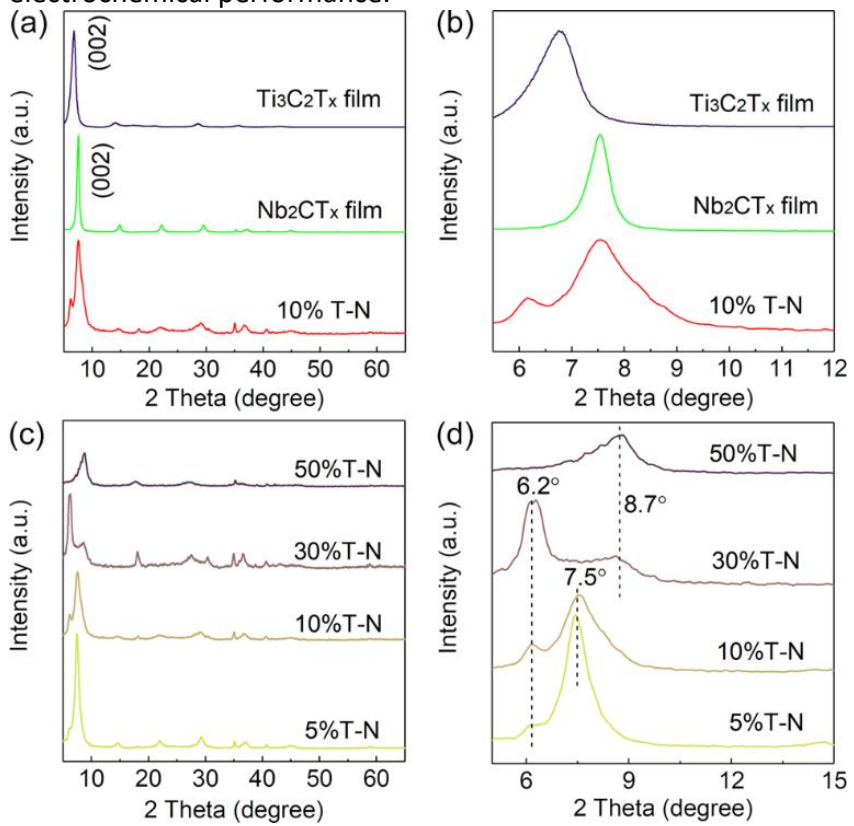

Fig. 3 (a-b) XRD patterns and magnified (002) peak region of the prepared $\mathrm{Ti}_{3} \mathrm{C}_{2} \mathrm{~T}_{\mathrm{x}}, \mathrm{Nb}_{2} \mathrm{CT}_{\mathrm{x}}$ and $10 \% \mathrm{~T}-\mathrm{N}$ films. (c-d) XRD patterns and magnified (002) peak region of the prepared hybrid $\mathrm{Ti}_{3} \mathrm{C}_{2} \mathrm{~T}_{\mathrm{x}} / \mathrm{Nb}_{2} \mathrm{CT}_{\mathrm{x}}$ films. 


\section{ARTICLE}
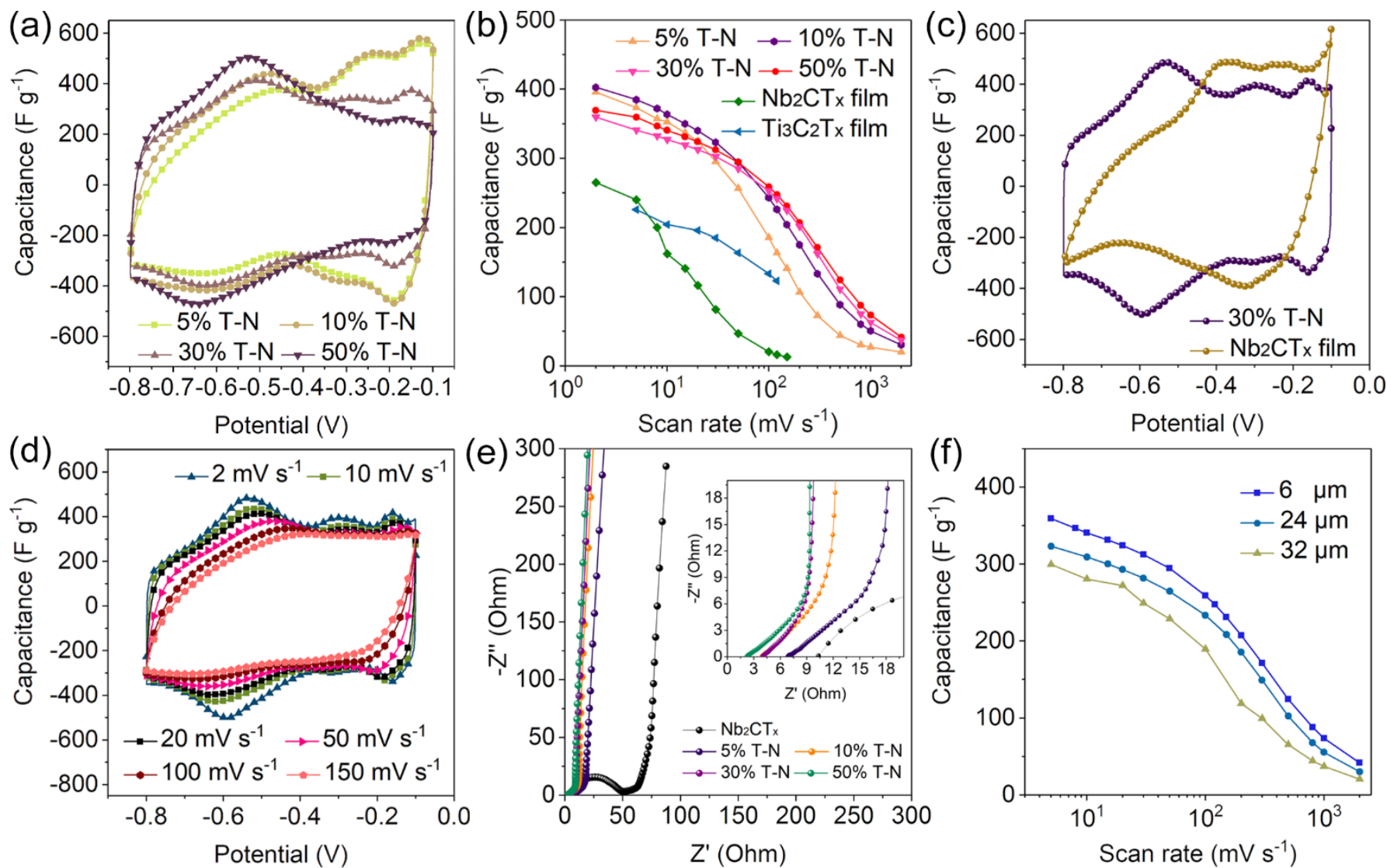

Fig. 4 Electrochemical performance of the prepared films in $2 \mathrm{M} \mathrm{H}_{2} \mathrm{SO}_{4}$ in a three-electrode configuration. (a) $\mathrm{CV}$ curves of $\mathrm{Ti}_{3} \mathrm{C}_{2} \mathrm{~T}_{\mathrm{x}} / \mathrm{Nb}_{2} \mathrm{CT}_{x}$ hybrid films with different mass ratios of $\mathrm{Ti}_{3} \mathrm{C}_{2} \mathrm{~T}_{\mathrm{x}}$ at a scan rate of $20 \mathrm{mV} \mathrm{s}^{-1}$. (b) Rate performance of hybrid $\mathrm{Ti}_{3} \mathrm{C}_{2} \mathrm{~T}_{\mathrm{x}} / \mathrm{Nb}_{2} \mathrm{CT}_{\mathrm{x}}, \mathrm{pure} \mathrm{Ti}_{3} \mathrm{C}_{2} \mathrm{~T}_{\mathrm{x}}$ and $\mathrm{Nb}_{2} \mathrm{CT}_{x}$ films at different scan rates. (c) Comparison of $\mathrm{CV}$ curves for $30 \% \mathrm{~T}-\mathrm{N}$ and pure $\mathrm{Nb}_{2} \mathrm{CT}_{x}$ films at a scan rate of $2 \mathrm{mV} \mathrm{s}{ }^{-1}$. (d) $\mathrm{CV}$ curves of the $30 \% \mathrm{~T}-\mathrm{N}$ hybrid film at different scan rates. (e) Electrochemical impedance spectroscopy data of $\mathrm{Nb}_{2} \mathrm{CT}_{\mathrm{x}}$ and $\mathrm{Ti}_{3} \mathrm{C}_{2} \mathrm{~T}_{\mathrm{x}} / \mathrm{Nb}_{2} \mathrm{CT}_{\mathrm{x}}$ hybrid films. The inset in e shows the magnified high-frequency region. (f) The thickness-dependent electrochemical performance of $30 \% \mathrm{~T}-\mathrm{N}$ hybrid film at different scan rates.

Compared to pure $\mathrm{Nb}_{2} \mathrm{CT}_{x}$ film, the prepared $\mathrm{Nb}_{2} \mathrm{CT}_{\mathrm{x}}$ based hybrid films possess excellent flexibility and significantly increased interlayer spacing due to the introduction of $\mathrm{Ti}_{3} \mathrm{C}_{2} \mathrm{~T}_{\mathrm{x}}$ nanosheets. Therefore, they are expected to present improved electrolyte ions accessibility, high specific capacitance and high rate capability, allowing them to be a potential candidate for flexible supercapacitors. The electrochemical performances of the $\mathrm{Ti}_{3} \mathrm{C}_{2} \mathrm{~T}_{\mathrm{x}} / \mathrm{Nb}_{2} \mathrm{CT}_{\mathrm{x}}$ films were characterized first in $2 \mathrm{M}$ sulphuric acid $\left(\mathrm{H}_{2} \mathrm{SO}_{4}\right)$ in a three-electrode configuration. The advantages of acidic electrolyte include excellent ionic conductivity and small size of protons known to allow for surface redox reactions. ${ }^{19}$ The cyclic voltammetry (CV) curves of $\mathrm{Ti}_{3} \mathrm{C}_{2} \mathrm{~T}_{\mathrm{x}} / \mathrm{Nb}_{2} \mathrm{CT}_{\mathrm{x}}$ films with different $\mathrm{Ti}_{3} \mathrm{C}_{2} \mathrm{~T}_{\mathrm{x}}$ contents at a scan rate of $20 \mathrm{mV} \mathrm{s}^{-1}$ are shown in Fig. 4a. The CV curves present three pairs of redox peaks in the entire potential window.

According to the previously reported results, ${ }^{11}$ that pair of broad redox peaks below $-0.4 \mathrm{~V}$ can be traced to the redox reaction occurred at the surface of $\mathrm{Ti}_{3} \mathrm{C}_{2} \mathrm{~T}_{\mathrm{x}}$. The other two pairs of redox peaks above $-0.4 \mathrm{~V}$ should be attributed to the pseudocapacitive behaviour of $\mathrm{Nb}_{2} \mathrm{CT}_{x}$. In acidic electrolyte, $\mathrm{H}^{+}$ insertion into $\mathrm{Nb}_{2} \mathrm{CT}_{\mathrm{x}}$ can be expressed as: $\mathrm{Nb}_{2} \mathrm{CT}_{\mathrm{x}}+\mathrm{yH}^{+}+\mathrm{ye} \mathrm{e}^{-} \Leftrightarrow$ $\mathrm{Nb}_{2} \mathrm{CT}_{x} \mathrm{H}_{y}$ ( $y$ is the mole fraction of the inserted $\mathrm{H}^{+}$). Considering the standard electrode potential of $\mathrm{Nb}$ element, the two pairs of redox peaks at about -0.15 and $-0.28 \mathrm{~V}$ can be attributed to the redox reactions occurring at the surface of $\mathrm{Nb}_{2} \mathrm{CT}_{\mathrm{x}}$, which change the oxidation state of $\mathrm{Nb}$, in a similar way than what was observed in $\mathrm{Ti}_{3} \mathrm{C}_{2}$.

It can be observed that dominant redox peaks change with the increase of the introduced $\mathrm{Ti}_{3} \mathrm{C}_{2} \mathrm{~T}_{\mathrm{x}}$. As for $30 \% \mathrm{~T}-\mathrm{N}$, its $\mathrm{CV}$ curves profiled quasi-rectangular shape, indicating that $\mathrm{Ti}_{3} \mathrm{C}_{2} \mathrm{~T}_{\mathrm{x}}$ 
and $\mathrm{Nb}_{2} \mathrm{CT}_{\mathrm{x}}$ almost contribute equivalent capacitance. The gravimetric capacitances of hybrid $\mathrm{Ti}_{3} \mathrm{C}_{2} \mathrm{~T}_{x} / \mathrm{Nb}_{2} \mathrm{CT}_{\mathrm{x}}$, pure $\mathrm{Ti}_{3} \mathrm{C}_{2} \mathrm{~T}_{\mathrm{x}}$ and $\mathrm{Nb}_{2} \mathrm{CT}_{\mathrm{x}}$ films at different scan rates calculated from $\mathrm{CV}$ results were shown in Fig. 4b. After combining $\mathrm{Nb}_{2} \mathrm{CT}_{x}$ with $\mathrm{Ti}_{3} \mathrm{C}_{2} \mathrm{~T}_{x}$, the hybrid films exhibited significantly improved gravimetric capacitance compared to the pure MXene films, which are attributed to the increased interlayer spacing and improved electrolyte ions accessibility. At $2 \mathrm{mV} \mathrm{s}^{-1}$, the gravimetric capacitance of $10 \% \mathrm{~T}-\mathrm{N}$ can reach up to $403 \mathrm{~F} \mathrm{~g}^{-1}$, while 265 and $245 \mathrm{~F} \mathrm{~g}^{-1}$ for pure $\mathrm{Nb}_{2} \mathrm{CT}_{x}$ and $\mathrm{Ti}_{3} \mathrm{C}_{2} \mathrm{~T}_{x}$ films, correspondingly. At $100 \mathrm{mV} \mathrm{s}^{-1}$, the gravimetric capacitances of $5,10,30$ and $50 \% \mathrm{~T}-\mathrm{N}$ films can retain 46.8, 60.3, 70.0 and $69.0 \%$ retention of initial value at $2 \mathrm{mV} \mathrm{s}^{-1}$, correspondingly. Among all hybrid films, 30\% T-N possessed the best rate performance. Even at high scan rate of $300 \mathrm{mV} \mathrm{s}^{-1}$, the capacitance of $30 \% \mathrm{~T}-\mathrm{N}$ can still retain $46.6 \%$ of the value at 2 $\mathrm{mV} \mathrm{s}-1$. Considering the practical application potential, 30\% T-N was regarded as the optimized hybrid film. From Fig. 4c, it can be seen that the $\mathrm{CV}$ curve of $30 \% \mathrm{~T}-\mathrm{N}$ is closer to quasi rectangular than that of pure $\mathrm{Nb}_{2} \mathrm{CT}_{\mathrm{x}}$ film, further demonstrating $30 \% \mathrm{~T}-\mathrm{N}$ can store energy at constant rate in its entire potential window. Indeed, the high capacitance

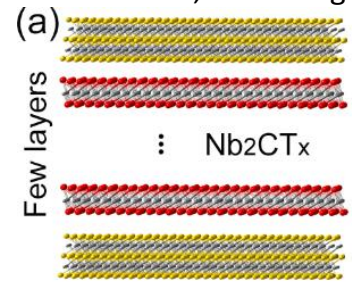

(b)
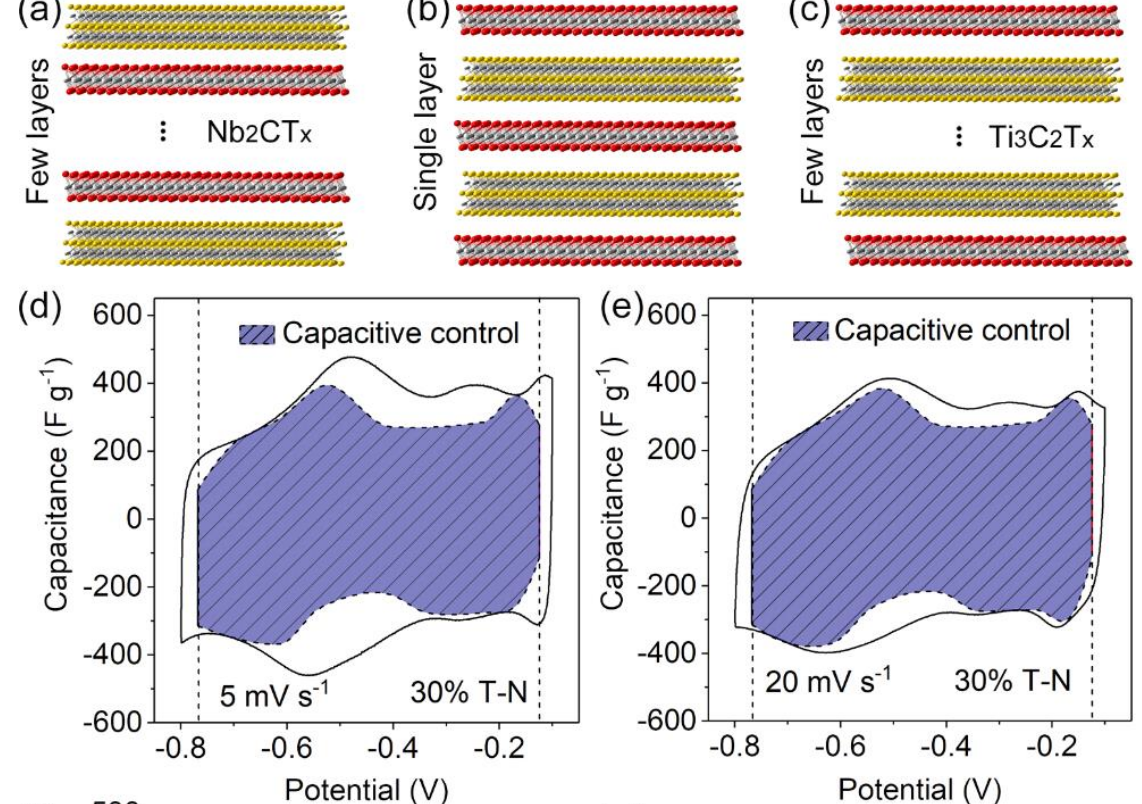

(f)
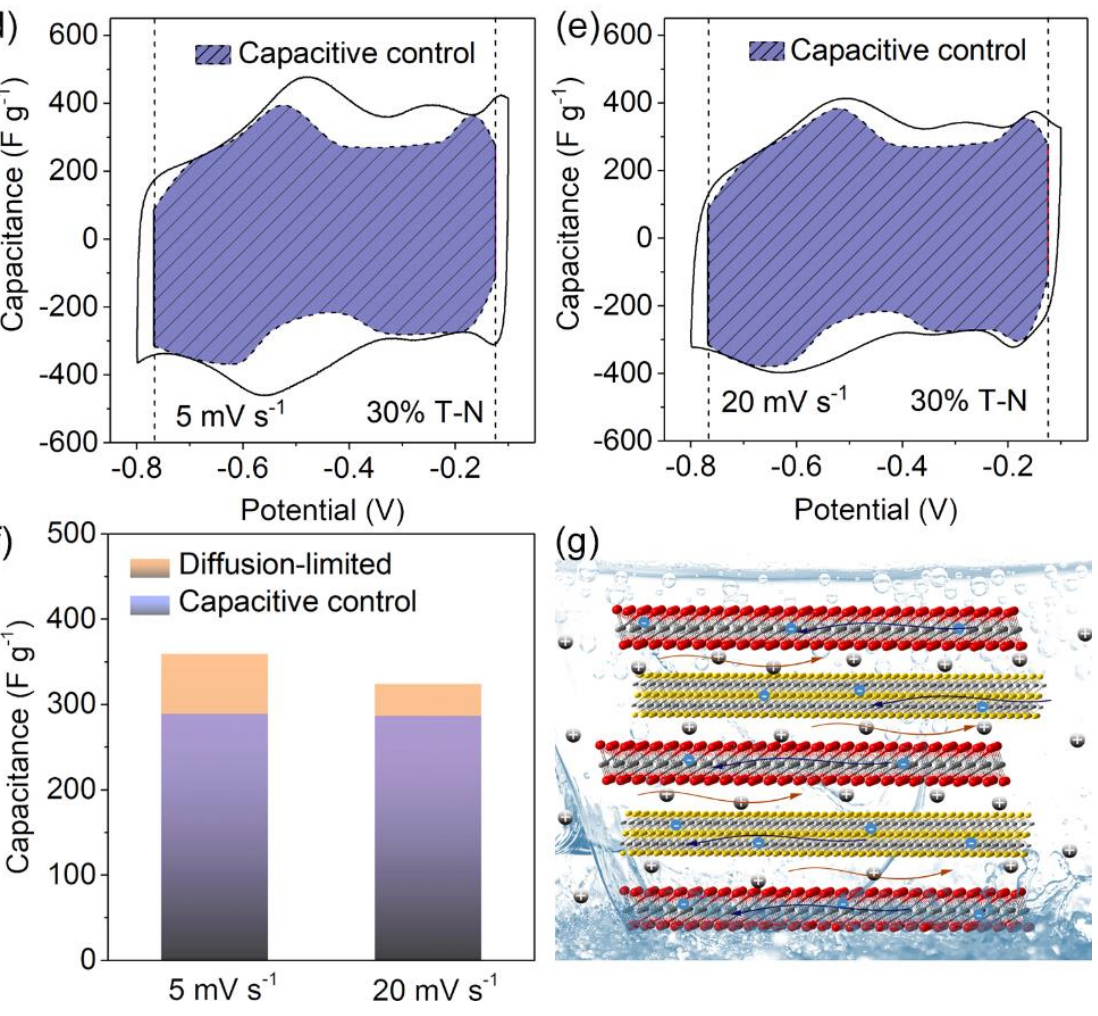

(g)

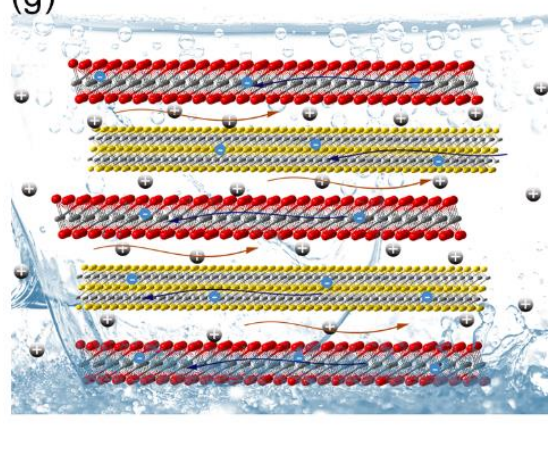

contribution potential ranges of pure MXene films are compensated by each other, leading to the continuous high capacitive performance for hybrid $30 \% \mathrm{~T}-\mathrm{N}$ in the entire potential window. The BET nitrogen adsorption-desorption isotherms and pore size distributions of the $\mathrm{Nb}_{2} \mathrm{CT}_{x}$ and allMXene hybrid films were also measured, as shown in Fig. S7-9. With the increase of $\mathrm{Ti}_{3} \mathrm{C}_{2} \mathrm{~T}_{\mathrm{x}}$ content, the BET surface area first increases and then decreases, with $30 \% \mathrm{~T}-\mathrm{N}$ reaching the maximum, although all values are relatively close and low compared to activated carbon. The high capacitance obtained despite the low surface areas is another suggestion that the good performance is mostly due to the redox pseudocapacitance rather than electrostatic double layer capacitance. All the films possess ideal pore size distribution (around $4 \mathrm{~nm}$, Fig. S7b, 8b) due to their two-dimensional stacking structure. The ICP analysis of the hybrid films was conducted and shown in Fig. S10. As expected, with the increase of the $\mathrm{Ti}_{3} \mathrm{C}_{2} \mathrm{~T}_{\mathrm{x}}$ nanosheets in the hybrid films, the mass ratio of Ti element goes up. The insertion of a small amount of $\mathrm{Ti}_{3} \mathrm{C}_{2} \mathrm{~T}_{x}$ can significantly improve the electrochemical performance of the all-MXene hybrid films, demonstrating the importance of combining $\mathrm{Ti}_{3} \mathrm{C}_{2} \mathrm{~T}_{\mathrm{x}}$ and $\mathrm{Nb}_{2} \mathrm{CT}_{\mathrm{x}}$.

Fig. 5 (a-c) Schematic illustration of $\mathrm{Ti}_{3} \mathrm{C}_{2} \mathrm{~T}_{\mathrm{x}} / \mathrm{Nb}_{2} \mathrm{CT}_{\mathrm{x}}$ hybrid films showing the different layer ratios of $\mathrm{Ti}_{3} \mathrm{C}_{2} \mathrm{~T}_{\mathrm{x}}$ to $\mathrm{Nb}_{2} \mathrm{CT}_{\mathrm{x}}$. (d-e) $\mathrm{Cyclic}_{\mathrm{c}}$ voltammetry profiles collected at $5 \mathrm{mV} \mathrm{s}^{-1}$ and $20 \mathrm{mV} \mathrm{s}^{-1}$ with hatched portions of the contributions of the processes not limited by diffusion. 
(f) The capacitive control and diffusion-limited contributions of the hybrid films, (g) The schematic diagram of the $30 \% \mathrm{~T}-\mathrm{N}$ used as electrode.

From the CV curves of 30\% T-N shown in Fig. 4d, it can be seen their integral areas at scan rates from 2 to $50 \mathrm{mV} \mathrm{s}^{-1}$ have no significant changes. Even at 100 and $150 \mathrm{mV} \mathrm{s}^{-1}$, the CV curves still remain the similar quasi-rectangular shape, indicating $30 \% \mathrm{~T}-\mathrm{N}$ possesses excellent rate performance. Fig. S11 represents the galvanostatic charge/discharge (GCD) curves of the $30 \% \mathrm{~T}-\mathrm{N}$ between -0.8 and $-0.1 \mathrm{~V}$ at different current densities from 0.5 to $10 \mathrm{~A} \mathrm{~g}^{-1}$. It can be observed that the GCD curves are almost linear and close to triangular shape, further confirming that hybrid 30\% T-N exhibited a typical capacitive characteristic, which is in consistent with the result of $\mathrm{CV}$ curves. In order to verify the effect of the $\mathrm{Ti}_{3} \mathrm{C}_{2} \mathrm{~T}_{\mathrm{x}}$ content on the electrochemical performance of the hybrid films, their electrochemical impedance spectroscopy (EIS) was performed at the same bias voltage of $-0.3 \mathrm{~V}$, as shown in Fig. 4e. The electrical equivalent circuit shown in Fig. S12 was used for fitting the impedance spectras. The detail fitting results are presented in Table S1. With the increase of $\mathrm{Ti}_{3} \mathrm{C}_{2} \mathrm{~T}_{\mathrm{x}}$ content, the equivalent series resistance of the hybrid films decreased gradually, indicating the increase of their conductivity. However, the $45^{\circ}$ angle section corresponding to ion migration limitation and charge transfer resistance of the hybrid films decreased first, but then increased, with the minima obtained with 30\% T-N reached. The low charge transfer resistance supports 30\% T-N optimal rate performance. In the low frequency region, all the EIS curves represented linear vertical profile, demonstrating that introducing of $\mathrm{Ti}_{3} \mathrm{C}_{2} \mathrm{~T}_{\mathrm{x}}$ nanosheets is favorable for the ions diffusion and transport.

Previously reported excellent energy storage performance of MXene based films is mostly based on thin electrode thickness. However, the development of thick film electrodes with high gravimetric capacitance is critical to the practical application of supercapacitors. Therefore, the electrochemical responses of hybrid $30 \% \mathrm{~T}-\mathrm{N}$ films with different thicknesses were compared, as shown in Fig. 4f. Although the gravimetric capacitances decreased with increased thickness, a high capacitance of $300 \mathrm{~F} \mathrm{~g}^{-1}$ remained for the $32-\mu \mathrm{m}$-thick $30 \% \mathrm{~T}-\mathrm{N}$ film, and $63.3 \%$ capacitance retention of that at $2 \mathrm{mV} \mathrm{s}^{-1}$ can be retained at high scan rate of $100 \mathrm{mV} \mathrm{s}^{-1}$. The high gravimetric capacitance and good rate performance of the 32- $\mu \mathrm{m}$-thick $30 \%$ T-N film demonstrates the combination of different MXenes can be an effective approach to improve the electrochemical performance of MXene based films for application as negative electrodes of hybrid large-scale energy storage devices.

In order to further investigate the effect of the $\mathrm{Ti}_{3} \mathrm{C}_{2} \mathrm{~T}_{\mathrm{x}}$ content on the electrochemical performances of hybrid films, the layer ratio of $\mathrm{Ti}_{3} \mathrm{C}_{2} \mathrm{~T}_{\mathrm{x}}$ to $\mathrm{Nb}_{2} \mathrm{CT}_{\mathrm{x}}$ in the hybrid electrodes were calculated. When the $\mathrm{Ti}_{3} \mathrm{C}_{2} \mathrm{~T}_{\mathrm{x}}$ content percent was low, for example 5 and $10 \% \mathrm{~T}-\mathrm{N}$, the $\mathrm{Nb}_{2} \mathrm{CT}_{\mathrm{x}}$ nanosheets can't be separated from each other by the introducing $\mathrm{Ti}_{3} \mathrm{C}_{2} \mathrm{~T}_{x}$ nanosheets, as schematically shown in Fig. $5 \mathrm{a}$. Taking account of the similar molecular weight of $\mathrm{Ti}_{3} \mathrm{C}_{2} \mathrm{~T}_{\mathrm{x}}$ to $\mathrm{Nb}_{2} \mathrm{CT}_{\mathrm{x}}$, optimal hybrid structure can be theoretically achieved when the content percent of both MXenes are almost equal, that is $50 \% \mathrm{~T}-\mathrm{N}$.
However, from the above XRD results (Fig. 3d) it can be estimated that in this work the delaminated $\mathrm{Nb}_{2} \mathrm{CT}_{\mathrm{x}}$ nanosheets are partially not exactly single-layer. As a result, the $\mathrm{Ti}_{3} \mathrm{C}_{2} \mathrm{~T}_{x}$ nanosheets in $50 \% \mathrm{~T}-\mathrm{N}$ are excessive, causing the restacking of $\mathrm{Ti}_{3} \mathrm{C}_{2} \mathrm{~T}_{\mathrm{x}}$, which schematic illustration is shown in Fig. $5 \mathrm{c}$. Compared to $50 \% \mathrm{~T}-\mathrm{N}$, the layer ratio of $\mathrm{Ti}_{3} \mathrm{C}_{2} \mathrm{~T}_{\mathrm{x}}$ to $\mathrm{Nb}_{2} \mathrm{CT}_{\mathrm{x}}$ in the hybrid $30 \% \mathrm{~T}-\mathrm{N}$ is probably closer to $1: 1$ (Fig. 5b) and the amount of $\mathrm{Ti}_{3} \mathrm{C}_{2} \mathrm{~T}_{\mathrm{x}}$ is just enough,ignoring the partial thick $\mathrm{Nb}_{2} \mathrm{CF}_{*}$ tayers. The optimized layer ratio in $30 \% \mathrm{~T}-\mathrm{N}$ makes it have high specific capacitance and good rate performance. To quantify the capacitive and diffusion limited contributions to the total capacitances of 30\% T-N, the Dunn's differentiation method was used. ${ }^{19}$ From the results summarized in Fig. $5 \mathrm{~d}$-e, it can be observed that, at low scan rate of $5 \mathrm{mV} \mathrm{s}^{-1}$, there is about $81 \%$ contribution of capacitive control processes to the total capacitance. At a scan rate of $20 \mathrm{mV} \mathrm{s}^{-1}$, the capacitive control contribution percent increased up to $90 \%$. The capacitive-control and diffusionlimited contributions were evaluated and presented in Fig. 5f. These analysis results demonstrate that the total capacitances of $30 \% \mathrm{~T}-\mathrm{N}$ derived mainly from surface capacitive effects, whether electrostatic or near-surface pseudocapacitive, which is benefited from the increased interlayer spacing and improved electrolyte ions accessibility due to the synergistic effect between $\mathrm{Ti}_{3} \mathrm{C}_{2} \mathrm{~T}_{\mathrm{x}}$ and $\mathrm{Nb}_{2} \mathrm{CT}_{\mathrm{x}}$ in the hybrids. As shown in Fig. $5 \mathrm{~g}$, the enhanced electrochemical performances of hybrid $30 \% \mathrm{~T}-\mathrm{N}$ such as high gravimetric capacitance and good rate performance can be attributed to the following aspects: (1) intercalation of $\mathrm{Ti}_{3} \mathrm{C}_{2} \mathrm{~T}_{\mathrm{x}}$ nanosheets between $\mathrm{Nb}_{2} \mathrm{CT}_{\mathrm{x}}$ layers could effectively impede the self-restacking of $\mathrm{Nb}_{2} \mathrm{CT}_{x}$ nanosheets while greatly increase the interlayer spacing of $\mathrm{Nb}_{2} \mathrm{CT}_{x}$ layers. (2) the $\mathrm{Ti}_{3} \mathrm{C}_{2} \mathrm{~T}_{x}$ nanosheets with large lateral sizes could act as conductive network and improve the mechanical strength of whole hybrid films. (3) the well-aligned alternating ordered structures of the hybrid films are favorable to electrolyte ions to rapidly diffuse and transport in hybrid film electrodes during the charge/discharge processes, leading to enhanced electrochemical surface utilization of MXene nanosheets.

The supercapacitors in $2 \mathrm{M} \mathrm{H}_{2} \mathrm{SO}_{4}$ electrolyte based on 30\% T-N were fabricated. Fig. 6a shows the CV curves of $30 \% \mathrm{~T}-\mathrm{N}$-based supercapacitors in $2 \mathrm{M} \mathrm{H}_{2} \mathrm{SO}_{4}$ at different scan rates. It can be seen that all the CV curves represent quasi-rectangle profiles, confirming that the supercapacitors exhibit typical capacitive performance. With the increase of scan rate, the CV curves maintain similar shapes without any obvious distortion, demonstrating promising rate capabilities. At $5 \mathrm{mV} \mathrm{s}^{-1}$, the supercapacitor delivered a specific capacitance of $88 \mathrm{~F} \mathrm{~g}^{-1}$. And even at $100 \mathrm{mV} \mathrm{s}^{-1}, 55.3 \%$ capacitance retention can be maintained. As shown in Fig. S13, the GCD curves of $30 \% \mathrm{~T}-\mathrm{N}$ based supercapacitors in $2 \mathrm{M} \mathrm{H}_{2} \mathrm{SO}_{4}$ at different current densities are linear and close to triangular shape, which are in accordance with the CV curves results in Figure 6 a.

In addition, all-solid-state supercapacitors based on 30\% T-N were assembled with $\mathrm{PVA}-\mathrm{H}_{2} \mathrm{SO}_{4}$ gel electrolyte. Obviously, the $\mathrm{CV}$ curves shown in Fig. $6 \mathrm{~b}$ gradually deviated from the quasi-rectangle profile with the increase of scan rate, which can be attributed to the limited ion penetration of the hybrid film electrodes. However, the 
all-solid-state supercapacitor delivered a specific capacitance of $81 \mathrm{~F}$ $\mathrm{g}^{-1}$ at $5 \mathrm{mV} \mathrm{s}^{-1}$, and $37 \mathrm{~F} \mathrm{~g}^{-1}$ at $100 \mathrm{mV} \mathrm{s}^{-1}$. As shown in Fig. $6 \mathrm{c}$, the discharging curves of the all-solid-state supercapacitor at different current densities maintained linear profiles, indicating typical capacitive characteristic. To investigate the flexibility of the assembled all-solid-state supercapacitor, its CV curves under different bending degrees are recorded and shown in Fig. 6d. It can be observed that the CV curves of the all-solid-state supercapacitor showed perfectly overlapped and negligible capacitance degradation at different bending angles, indicating the excellent mechanical stability and flexibility. To further investigate the potential of the assembled all-solid-state supercapacitor applications, the long-term cycling stability was evaluated by repeating the GCD test at $2 \mathrm{~A} \mathrm{~g}^{-1}$ for 10,000 cycles. After 10,000 charging/discharging cycles, the capacitance retention can maintain $94 \%$, demonstrating that the allsolid-state supercapacitors exhibit excellent cycling stability (Fig. 6e). attributed to partially irreversible redox reactions, which might potentially lead to oxidation and degradation of $\mathrm{Nb}_{2} \mathrm{CT}_{\mathrm{x}}$. Moreover, the electrochemical performance of the assembled $30 \% \mathrm{~T}-\mathrm{N}$ based supercapacitors in this work were compared with other state-of-theart MXene-based supercapacitors, as shown in the Ragone plots in Fig. $6 \mathrm{f}$. The energy density of the supercapacitor in $2 \mathrm{M} \mathrm{H}_{2} \mathrm{SO}_{4}$ can reach 5.7 and $2.3 \mathrm{mWh} \mathrm{g}^{-1}$ at power density of 172.5 and $3000.0 \mathrm{~mW}$ $\mathrm{g}^{-1}$, respectively. As for the all-solid-state supercapacitor with PVA$\mathrm{H}_{2} \mathrm{SO}_{4}, 5.5$ and $1.1 \mathrm{mWh} \mathrm{g}^{-1}$ can be delivered at 141.4 and $2350.0 \mathrm{~mW}$ $\mathrm{g}^{-1}$, respectively. Compared to the previous reported MXene-based and carbon-based supercapacitors, the $\mathrm{Ti}_{3} \mathrm{C}_{2} \mathrm{~T}_{x} / \mathrm{Nb}_{2} \mathrm{CT}_{\mathrm{x}}$ based supercapacitors in this work can deliver high energy densities at high power densities, which ensures them serve as promising power source units for wearable electronics applications. The detailed comparison results were listed in Table S2 and S3 in supporting information.
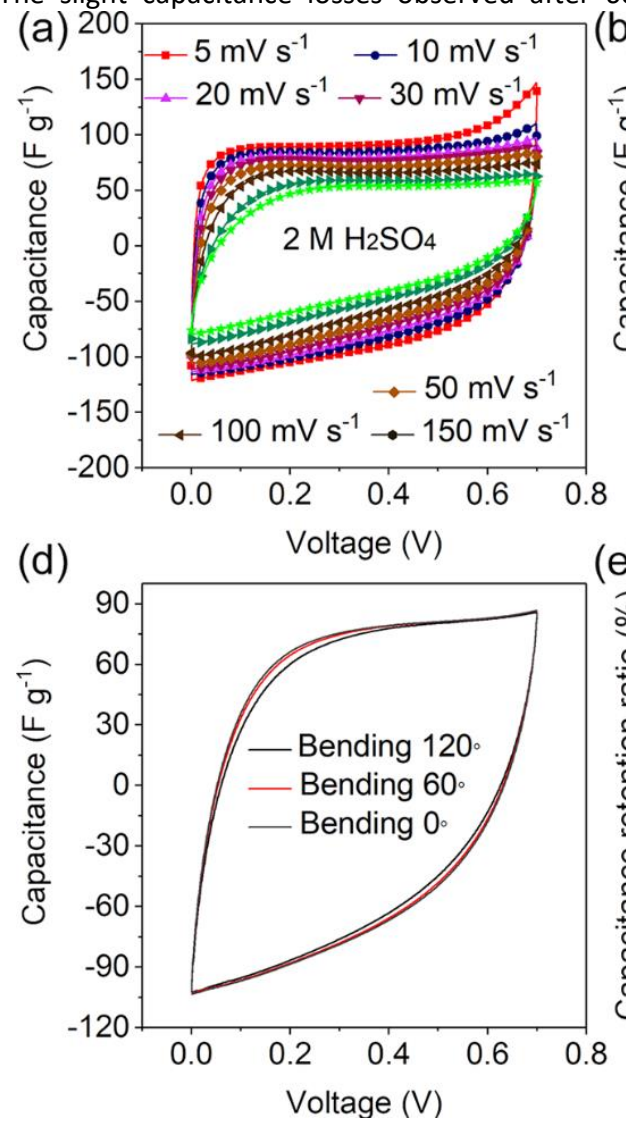
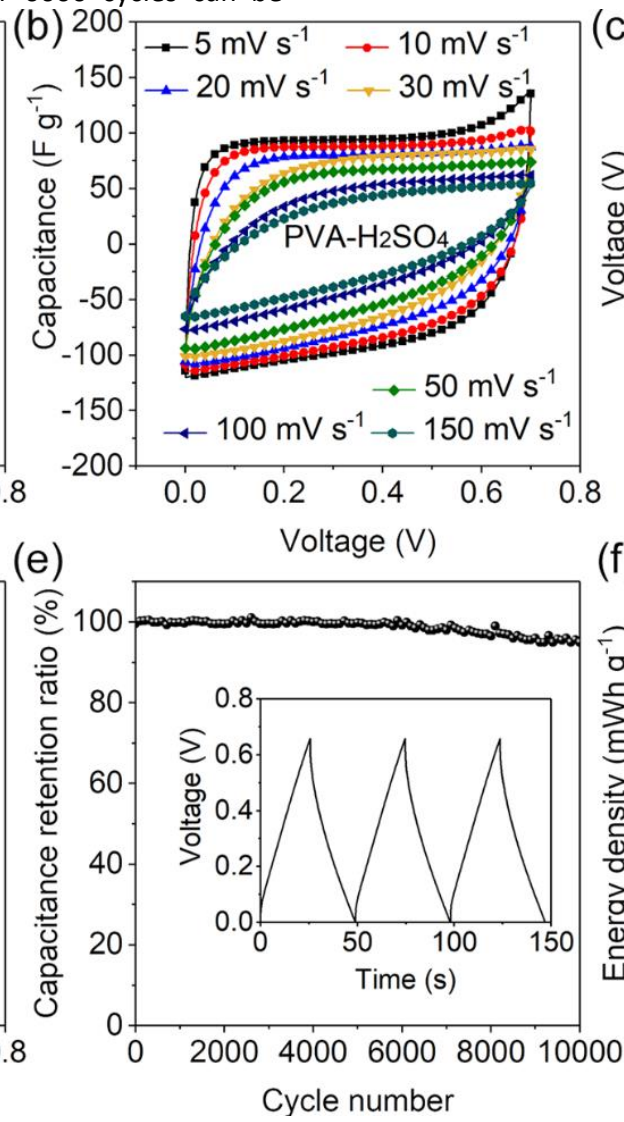

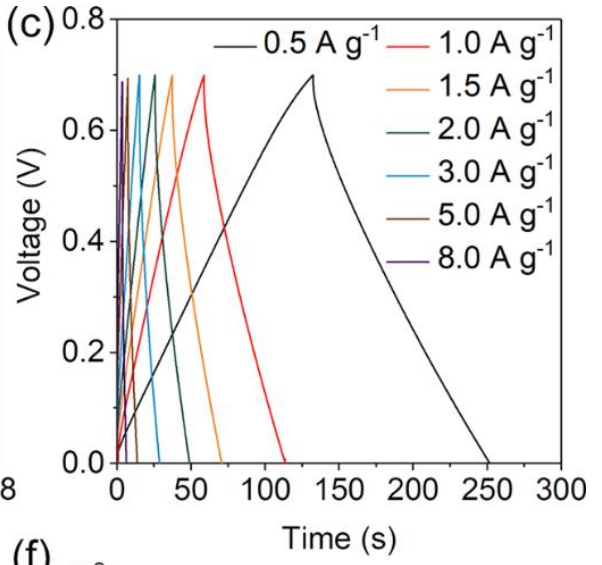

(f)

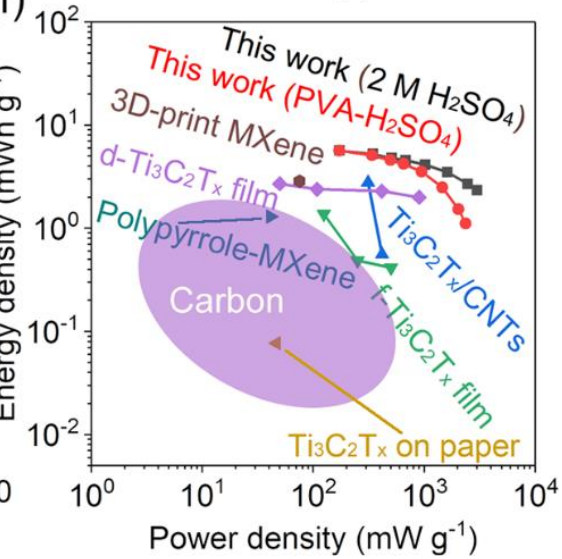

Fig. 6 Electrochemical performance of the fabricated supercapacitors. CV curves of $30 \% \mathrm{~T}-\mathrm{N}$-based supercapacitors (a) in $2 \mathrm{M} \mathrm{H}_{2} \mathrm{SO}_{4}$ electrolyte and (b) with PVA- $\mathrm{H}_{2} \mathrm{SO}_{4}$ gel at different scan rates. (c) $\mathrm{GCD}$ curves of $30 \% \mathrm{~T}-\mathrm{N}$-based supercapacitors with $\mathrm{PVA}^{-} \mathrm{H}_{2} \mathrm{SO}_{4}$ gel at different current densities. (d) $\mathrm{CV}$ curves of the all-solid-state supercapacitors bended at different angles of $0^{\circ}, 60^{\circ}$ and $120^{\circ}$ at $30 \mathrm{mV} \mathrm{s}$. (e) The capacitance retention of the all-solid-state supercapacitors after 10, 000 cycles at $2 \mathrm{~A} \mathrm{~g}^{-1}$. The inset is the last three charge-discharge cycles. (f) Ragone plots of the fabricated supercapacitors in this work and the other state-of-the-art MXene-based and carbon-based supercapacitors from the literature.

To further explore the practical application of the fabricated allsolid-state supercapacitors in portable electronic devices, we integrated the flex sensor together with the supercapacitor to fabricate integrated self-powered sensing devices, which schematic illustration is shown in Fig. 7a. The flex sensor was connected in series with the supercapacitor, where the all-solid-state supercapacitor serves as power source of the integrated device, as shown in the schematic circuit diagram (Fig. 7a). The flex sensor is basically a variable resistor that reacts to bends, which resistance increases with the increasing bending degree. Under different 
bending angles, the current response in the circuit is not the same, indicating the bending degree of the device. The working principle diagram of the flex sensor is shown in Fig. S14. From the selfdischarge curve of the all-solid-state supercapacitor shown in Fig. 7b, it can be seen that the open-circuit voltage can remain about $0.5 \mathrm{~V}$ after $1000 \mathrm{~s}$, confirming the feasibility to use it as power source to drive the flex sensor. The integrated flex sensor can be used to detect the finger bending angle, as shown in Fig. 7c. When the finger bended and relaxed, the movements could be tracked by the integrated flex sensor and subsequently transformed into electronic output. To acquire the current response value at each bending angle, the current responses of the integrated flex sensor for different bending angles were measured and presented in Fig. $7 \mathrm{~d}$. It can be observed that the sensing response intensity increased with the increasing bending degrees from $30^{\circ}$ to $180^{\circ}$. All of the above experimental results indicate the $\mathrm{Ti}_{3} \mathrm{C}_{2} \mathrm{~T}_{\mathrm{x}} / \mathrm{Nb}_{2} \mathrm{CT}_{\mathrm{x}}$-based all-solid-state supercapacitor can be used as stable power source units for portable electronic devices and medical microdevices.

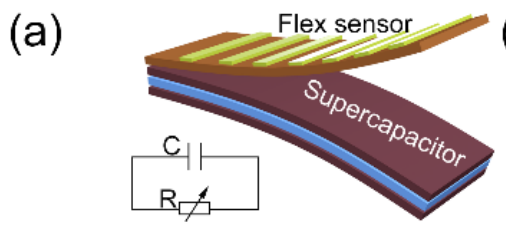

(b)

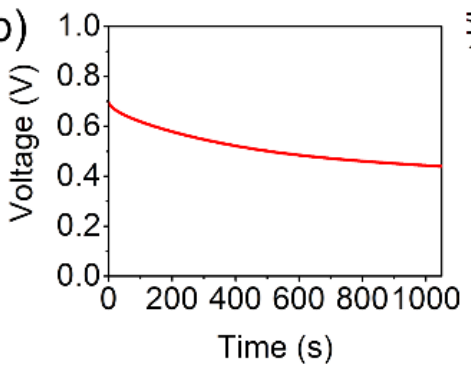

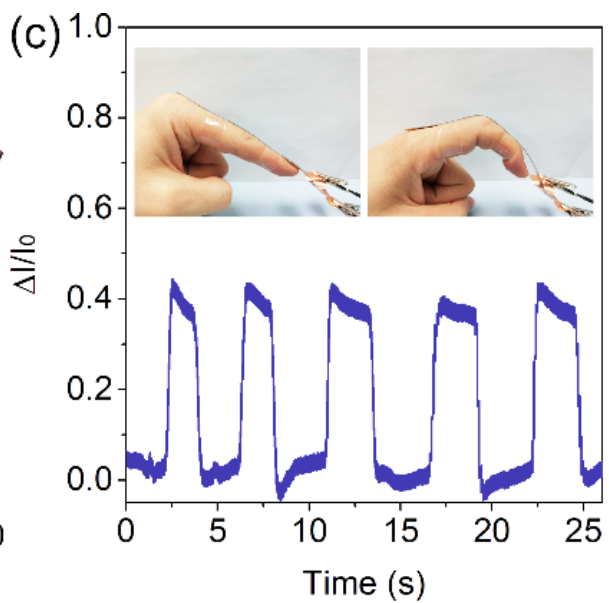

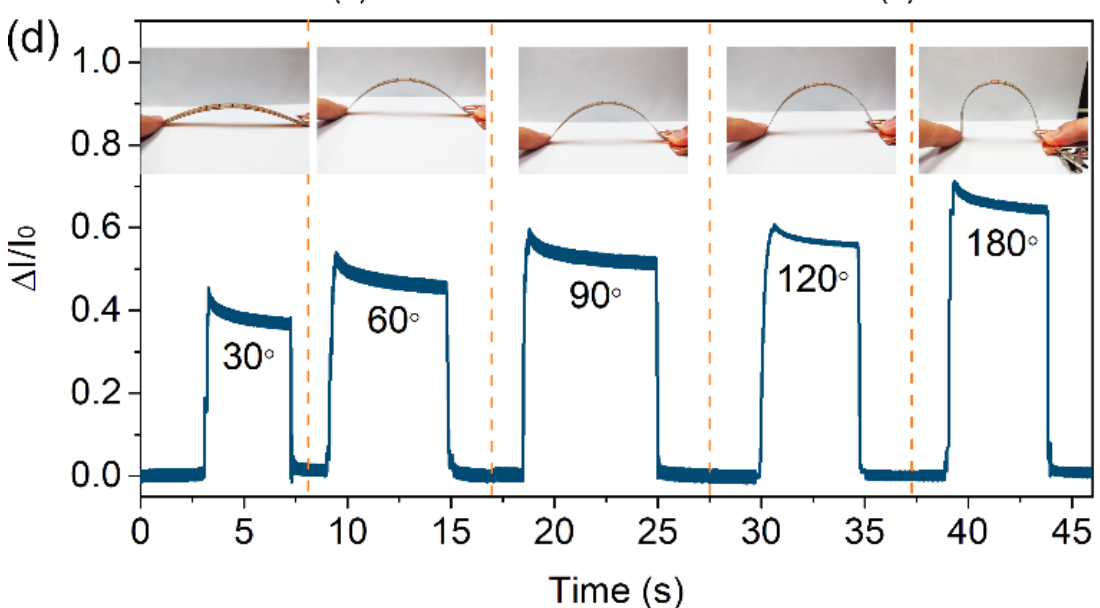

Fig. 7 (a) Schematic illustration of the integrated self-powered flex sensor, where the all-solid-state supercapacitor serves as power source. (b) The self-discharge curve of the all-solid-state supercapacitor. (c) Sensing responses for finger joint movement. (d) Sensing responses of the integrated flex sensor for different bending angles. $\Delta$ l denotes the change of the current before and after the bending, and $\mathrm{I}_{0}$ is the current when no bending is applied.

\section{Conclusions}

In summary, it's proposed that stacking few-layer $\mathrm{Nb}_{2} \mathrm{CT}_{x}$ with $\mathrm{Ti}_{3} \mathrm{C}_{2} \mathrm{~T}_{\mathrm{x}}$ nanosheets into composite structures is a simple and effective approach to improve the electrochemical performance of $\mathrm{Nb}_{2} \mathrm{CT}_{x}$-based films for supercapacitors. The intercalated $\mathrm{Ti}_{3} \mathrm{C}_{2} \mathrm{~T}_{\mathrm{x}}$ nanosheets between $\mathrm{Nb}_{2} \mathrm{CT}_{\mathrm{x}}$ layers effectively increase the interlayer spacing of $\mathrm{Nb}_{2} \mathrm{CT}_{x}$ layers and impede the self-restacking of $\mathrm{Nb}_{2} \mathrm{CT}_{\mathrm{x}}$ nanosheets, which are favorable to electrolyte ions to rapidly diffuse and transport in the hybrid electrodes. The optimized $\mathrm{Ti}_{3} \mathrm{C}_{2} \mathrm{~T}_{\mathrm{x}} / \mathrm{Nb}_{2} \mathrm{CT}_{\mathrm{x}}$ films possess enhanced capacitive performance and rate performance. A gravimetric capacitance of $370 \mathrm{~F} \mathrm{~g}^{-1}$ can be delivered at $2 \mathrm{mV} \mathrm{s}^{-1}$, and $56.1 \%$ capacitance retention at high scan rate of $200 \mathrm{mV} \mathrm{s}^{-1}$. The energy density of the assembled allsolid-state supercapacitors can reach $5.5 \mathrm{mWh} \mathrm{g}^{-1}$ at power density of $141.4 \mathrm{~mW} \mathrm{~g}^{-1}$, and $1.1 \mathrm{mWh} \mathrm{g}^{-1}$ at high power density of $2350.0 \mathrm{~mW} \mathrm{~g}^{-1}$. The all-solid-state supercapacitors presented good flexibility and long cycling life. The all-solid-state supercapacitor was also integrated with a flex sensor to fabricated self-powered device, where all-solid-state supercapacitor served as stable power source unit to drive the flex sensor. The route to fabricate $\mathrm{Ti}_{3} \mathrm{C}_{2} \mathrm{~T}_{\mathrm{x}} / \mathrm{Nb}_{2} \mathrm{CT}_{\mathrm{x}}$ hybrid film is

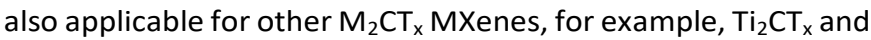


$\mathrm{V}_{2} \mathrm{CT}_{\mathrm{x}}$, improving the application potential of MXenes for flexible supercapacitors and integrated electronic devices.

\section{Experimental}

\subsection{Synthesis of $\mathrm{Ti}_{3} \mathrm{~A} / \mathrm{C}_{2}$ and $\mathrm{Nb}_{2} \mathrm{AlC}$ phase}

$\mathrm{Ti}_{3} \mathrm{AlC}_{2}$ was synthesized as described in our previous work. ${ }^{14}$ Typically, $\mathrm{TiH}_{2}, \mathrm{Al}$, and TiC powders were mixed in 1: 1.2: 2 mole ratio, and ball milled for $24 \mathrm{~h}$ followed by sintering in a tube oven at 1450 ${ }^{\circ} \mathrm{C}$ in a corundum crucible and kept at that temperature for $2 \mathrm{~h}$ in a flowing Ar atmosphere. Crushing and sieving the resulting compact powder, $\mathrm{Ti}_{3} \mathrm{AlC}_{2}$ powder with size of $<38 \mu \mathrm{m}$ was obtained. The $\mathrm{Nb}_{2} \mathrm{AlC}$ powders were made by mixing elemental $\mathrm{Nb}, \mathrm{Al}$ and $\mathrm{C}$ powders in a 2:1.1:1 molar ratio. The mixed powders were ball-milled for $12 \mathrm{~h}$ and cold-pressed into cylindrical discs. Then the discs were sintered at $1600{ }^{\circ} \mathrm{C}$ for $4 \mathrm{~h}$ in a flowing $\mathrm{Ar}$ atmosphere. Finally, the resultant discs were ball milled and sieved through a 400 mesh screen to obtain $\mathrm{Nb}_{2} \mathrm{AlC}$ powder with particle size of $<38 \mu \mathrm{m}$.

\subsection{Preparation of few-layer $\mathrm{Ti}_{3} \mathrm{C}_{2} T_{x}$ suspension}

Few-layer $\mathrm{Ti}_{3} \mathrm{C}_{2} \mathrm{~T}_{\mathrm{x}}$ suspension was synthesized by etching $\mathrm{Ti}_{3} \mathrm{AlC}_{2} \mathrm{MAX}$ powder in $\mathrm{LiF} / \mathrm{HCl}$ hybrid etchant according to the previously reported route. ${ }^{8}$ Typically, a total of $3.0 \mathrm{~g}$ of $\mathrm{Ti}_{3} \mathrm{AlC}_{2}$ precursor powder was gradually added (over the course of $5 \mathrm{~min}$ ) to $\mathrm{LiF}(4.8 \mathrm{~g}) / \mathrm{HCl}(60$ $\mathrm{mL}, 9 \mathrm{M})$ mixture. Then the mixture was left under continuous stirring at room temperature for $24 \mathrm{~h}$. Afterward, the resultant acidic mixture was washed copiously with deionized water via centrifugation at $3500 \mathrm{rpm}$ several times for $5 \mathrm{~min}$ per cycle until a stable dark-green supernatant solution, with a $\mathrm{pH}$ of $\geq 6$, was obtained. Adding water to the sediment and manually shaking it for several minutes, delaminated $\mathrm{Ti}_{3} \mathrm{C}_{2} \mathrm{~T}_{\mathrm{x}}$ nanosheets can be obtained. After $1 \mathrm{~h}$ centrifugation at $3500 \mathrm{rpm}$, few-layer $\mathrm{Ti}_{3} \mathrm{C}_{2} \mathrm{~T}_{\mathrm{x}}$ suspension with concentration of $\sim 1.5 \mathrm{mg} \mathrm{ml}^{-1}$ was prepared.

\subsection{Preparation of few-layer $\mathrm{Nb}_{2} \mathrm{CT}_{x}$ suspension}

A total of $3.0 \mathrm{~g}$ of $\mathrm{Nb}_{2} \mathrm{AlC}$ powder was added gradually (in the course of $5 \mathrm{~min}$ ) to $30 \mathrm{~mL}$ of $50 \mathrm{wt} \% \mathrm{HF}$ while stirring. The mixture was heated and held at $30{ }^{\circ} \mathrm{C}$ for $24 \mathrm{~h}$ in an oil bath. Subsequently, the mixture was washed five times via centrifugation. The obtained wet sediment was dispersed in $60 \mathrm{~mL}$ of $1 \mathrm{wt} \%$ tetramethylammonium hydroxide (TMAOH) solution for $6 \mathrm{~h}$ at room temperature. Then the resultant wet sediment was washed via centrifugation and the fewlayer $\mathrm{Nb}_{2} \mathrm{CT}_{\mathrm{x}}$ suspension with concentration of $\sim 1.0 \mathrm{mg} \mathrm{ml}^{-1}$ was obtained.

\subsection{Fabrication of hybrid $\mathrm{Ti}_{3} \mathrm{C}_{2} \mathrm{~T}_{x} / \mathrm{Nb}_{2} \mathrm{CT}_{x}$ films}

Few-layer $\mathrm{Nb}_{2} \mathrm{CT}_{x}$ and $\mathrm{Ti}_{3} \mathrm{C}_{2} \mathrm{~T}_{\mathrm{x}}$ suspensions were separately mixed in certain weight ratios, yielding a series of hybrid $\mathrm{Ti}_{3} \mathrm{C}_{2} \mathrm{~T}_{x} / \mathrm{Nb}_{2} \mathrm{CT}_{x}$ suspensions with different initial Ti3C2Tx contents $(5,10,30,50 \mathrm{wt}$ \%). Subsequently, each hybrid $\mathrm{Ti}_{3} \mathrm{C}_{2} \mathrm{~T}_{\mathrm{x}} / \mathrm{Nb}_{2} \mathrm{CT}_{\mathrm{x}}$ suspension was filtered using a polypropylene membrane (Celgard, pore size 0.064 $\mu \mathrm{m})$. After drying, the hybrid $\mathrm{Ti}_{3} \mathrm{C}_{2} \mathrm{~T}_{\mathrm{x}} / \mathrm{Nb}_{2} \mathrm{CT}_{\mathrm{x}}$ films were peeled easily from the membrane, and labeled as 5\% T-N, 10\% T-N, 30\% T-N and $50 \% \mathrm{~T}-\mathrm{N}$ according to the $\mathrm{Ti} 3 \mathrm{C} 2 \mathrm{~T} x$ contents, respectively.

\subsection{Assembly of the symmetric supercapacitors}

The symmetric supercapacitors in $2 \mathrm{M} \mathrm{H}_{2} \mathrm{SO}_{4}$ were assembled with two flexible $30 \%$ T-N films with the exact same size of $0.8 * 3.0 \mathrm{~cm}^{2}$ separated by a Celgard membrane used as separator. The all-solid- state symmetric supercapacitors were assembled with two flexible $30 \% \mathrm{~T}-\mathrm{N}$ films with the exact same size of $0.8 * 3.0 \mathrm{~cm}^{2}$, in which PVA$\mathrm{H}_{2} \mathrm{SO}_{4}$ gel served as separator and electrolyte. The $\mathrm{PVA}^{-} \mathrm{H}_{2} \mathrm{SO}_{4}$ gel electrolyte was prepared as follows: Approximately $3 \mathrm{~g}$ of PVA was dispersed into $30 \mathrm{~mL}$ of deionized water at $90{ }^{\circ} \mathrm{C}$ with constant stirring until a transparent solution of PVA was obtained. Then $3 \mathrm{~g}$ of $\mathrm{H}_{2} \mathrm{SO}_{4}$ was added to the PVA solution and stirred gently to obtain homogeneous PVA- $\mathrm{H}_{2} \mathrm{SO}_{4}$ gel electrolyte.

\subsection{Assembly of the integrated self-powered sensing devices}

The flex sensor (RB-02S046, Suzhou changxian optoelectronic technology co. LTD) with size of $1.0 * 9.0 \mathrm{~cm}^{2}$ was connected in series with the assembled all-solid-state supercapacitor using conductive silver paint to fabricate the integrated self-powered flex sensor. The flex sensor is a polymer thick film device, which is basically a variable resistor that reacts to bends, which resistance increases with the increasing bending degree.

\subsection{Materials characterizations}

The nanomaterial phases were characterized using a powder X-ray diffractometer (XRD, Bruker, D8 ADVANCE) with Cu Ka radiation ( $\lambda=$ $0.15406 \mathrm{~nm}$ ). The morphology of the nanomaterials was confirmed using a MEGALLAN 400 scanning electron microscope (SEM) and a transmission electron microscope (TEM) (JEOL JEM-2100, Japan), with an accelerating voltage of $200 \mathrm{kV}$. The TEM samples were prepared by placing several drops of the material dispersion in alcohol onto a copper grid and air drying. The ICP analysis was conducted to measure the $\mathrm{Ti}$ and $\mathrm{Nb}$ contents in the hybrid films. The BET nitrogen adsorption-desorption isotherms were used to evaluate the surface area.

\subsection{Electrochemical measurements}

All the electrochemical tests (cyclic voltammetry (CV), galvanostatic charge/discharge (GCD), electrochemical impedance spectroscopy (EIS) and galvanostatic cycling) were evaluated using an electrochemical workstation ( $\mathrm{CHI} 760 \mathrm{e}$ ). The electrochemical performance of the hybrid $\mathrm{Ti}_{3} \mathrm{C}_{2} \mathrm{~T}_{\mathrm{x}} / \mathrm{Nb}_{2} \mathrm{CT}_{\mathrm{x}}$ films were measured first with three-electrode Swagelok cells, where the hybrid $\mathrm{Ti}_{3} \mathrm{C}_{2} \mathrm{~T}_{\mathrm{x}} / \mathrm{Nb}_{2} \mathrm{CT}_{\mathrm{x}}$ films ( $5 \mathrm{~mm}$-diameter disks with mass loadings of $0.6,2.4$ and $3.2 \mathrm{mg}$ $\mathrm{cm}^{-2}$, respectively) were directly used as the working electrode, overcapacitive activated carbon was the counter electrode, a $\mathrm{Hg} / \mathrm{HgSO}_{4}$ electrode was used as the reference electrode, and $2 \mathrm{M}$ $\mathrm{H}_{2} \mathrm{SO}_{4}$ aqueous solution was the electrolyte. Electrochemical impedance spectroscopy was performed at open circuit potential, with a $10-\mathrm{mV}$ amplitude, and frequencies that ranged from $10 \mathrm{mHz}$ to $100 \mathrm{kHz}$. The current signal of the integrated flex sensor was measured using CHI760E electrochemical workstation, where the amperometric i-t curve technique was selected.

Gravimetric capacitance $\left(C_{m}\right)$ can be calculated from the CV curves according to the following equation:

$$
C_{m}=\frac{S}{2 m v U}(1)
$$

where $S$ is the integrating area of the $C V$ curve, $m$ is the mass of the hybrid film electrode, $v$ is the scan rate, and $U$ is the potential window.

The gravimetric energy densities $\left(E_{M}\right)$ as well as power density $\left(\mathrm{P}_{M}\right)$ were calculated according to the following equations:

$$
E_{M}=\frac{1}{2} C_{M} U^{2}
$$




$$
P_{M}=\frac{E_{M}}{\Delta t}
$$

where $\Delta t$ is the discharge time. $C_{M}, E_{M}$ and $P_{M}$ are calculated taking into account the total weight of both electrodes (M).

The detailed process to obtain the capacitive control contribution using Dunn's differentiation method is described in SI.

\section{Conflicts of interest}

There are no conflicts to declare.

\section{Acknowledgements}

This work was supported by the National Natural Science Foundation of China (Grant No. 51571065 and No. 11875032), the Innovation-Driven Development Foundation of Guangxi Province (Grant no. AA17204063), and the Doctoral foundation program of Guangxi University (A3120051013).

\section{References}

1 Y. Wang, Y. Song and Y. Xia, Chem. Soc. Rev., 2016, 45, 5925-5950. 2 K. Jost, G. Diona and Y. Gogotsi, J. Mater. Chem. A, 2014, 2, 1077610787.

3 V. Augustyn, P. Simon and B. Dunn, Energ. Environ. Sci., 2014, 7, 1597-1614.

4 B. Mendoza-Sánchez and Y. Gogotsi, Advanced Materials, 2016, 28 , 6104-6135.

5 M. Naguib, O. Mashtalir, J. Carle, V. Presser, J. Lu, L. Hultman, Y. Gogotsi and M. W. Barsoum, ACS Nano, 2012, 6, 1322-1331.

6 M. Naguib, M. Kurtoglu, V. Presser, J. Lu, J. J. Niu, M. Heon, L. Hultman, Y. Gogotsi and M. W. Barsoum, Advanced Materials, 2011, 23, 4248-4253.

7 B. Anasori, M. R. Lukatskaya and Y. Gogotsi, Nat. Rev. Mater., 2017, 2, 16098 .

8 M. Alhabeb, K. Maleski, B. Anasori, P. Lelyukh, L. Clark, S. Sin and Y. Gogotsi, Chemistry of Materials, 2017, 29, 7633-7644.

9 O. Mashtalir, M. R. Lukatskaya, M.-Q. Zhao, M. W. Barsoum and Y. Gogotsi, Advanced Materials, 2015, 27, 3501-3506.

10 O. Mashtalir, M. Naguib, V. N. Mochalin, Y. Dall'Agnese, M. Heon, M. W. Barsoum and Y. Gogotsi, Nat. Commun., 2013, 4, 1716.

11 M. R. Lukatskaya, S. Kota, Z. Lin, M.-Q. Zhao, N. Shpigel, M. D. Levi, J. Halim, P.-L. Taberna, M. W. Barsoum, P. Simon and Y. Gogotsi, Nat. Energy, 2017, 2, 17105.

12 J. Halim, S. Kota, M. R. Lukatskaya, M. Naguib, M.-Q. Zhao, E. J. Moon, J. Pitock, J. Nanda, S. J. May, Y. Gogotsi and M. W. Barsoum, Advanced Functional Materials, 2016, 26, 3118-3127.

13 J. Li, X. Yuan, C. Lin, Y. Yang, L. Xu, X. Du, J. Xie, J. Lin and J. Sun, Adv. Energy Mater., 2017, 7, 1602725.

14 S. Xu, Y. Dall'Agnesea, G. Wei, C. Zhang, Y. Gogotsi and W. Han, Nano Energy, 2018, 50, 479-488.

15 Chenhui Yang, Y. T., Yapeng Tian, Yangyang Luo, Xingtian Yin, and Wenxiu Que, ACS Appl. Energy Mater., 2020, 3, 586-596.

16 Y. Tian, W. Que, Y. Luo, C. Yang, X. Yin and L. B. Kong, J. Mater. Chem. A, 2019, 7, 5416-5425.

17 M. Zhu, Y. Huang, Q. Deng, J. Zhou, Z. Pei, Q. Xue, Y. Huang, Z. Wang, H. Li, Q. Huang and C. Zhi, Adv. Energy Mater., 2016, 6, 1600969.

18 X. Zhao, M. Liu, Y. Chen, B. Hou, N. Zhang, B. Chen, N. Yang, K. Chen, J. Li and L. An, J. Mater. Chem. A, 2015, 3, 7870-7876.
19 M. Ghidiu, M. R. Lukatskaya, M. Q. Zhao, Y. Gogotsi and M. W. Barsoum, Nature, 2014, 516, 78-81.

20 S. Xu, G. Wei, J. Li, Y. Ji, N. Klyui, V. Izotov and W. Han, Chemical Engineering Journal, 2017, 317, 1026-1036.

21 M.-Q. Zhao, C. E. Ren, Z. Ling, M. R. Lukatskaya, C. Zhang, K. L. V. Aken, M. W. Barsoum and Y. Gogotsi, Advanced Materials, 2015, 27, 339-345.

22 Z. Fan, Y. Wang, Z. Xie, D. Wang, Y. Yuan, H. Kang, B. Su, Z. Cheng and Y. Liu, Adv. Sci., 2018, 5, 1800750.

23 J. Yan, C. E. Ren, K. Maleski, C. B. Hatter, B. Anasori, P. Urbankowski, A. Sarycheva and Y. Gogotsi, Advanced Functional Materials, 2017, 27, 1701264.

24 Z. Ling, C. E. Ren, M.-Q. Zhao, J. Yang, J. M. Giammarco, J. Qiu, M. W. Barsoum and Y. Gogotsi, P. Natl. Acad. Sci. USA, 2014, 111 16676-16681.

25 F. Shahzad, M. Alhabeb, C. B. Hatter, B. Anasori, S. M. Hong, C. M. Koo and Y. Gogotsi, Science, 2016, 353, 1137-1140.

26 S. Xu, G. Wei, J. Li, W. Han and Y. Gogotsi, J. Mater. Chem. A, 2017, 5, 17442-17451.

27 M. Boota, B. Anasori, C. Voigt, M.-Q. Zhao, M. W. Barsoum and Y. Gogotsi, Advanced Materials, 2016, 28, 1517-1522.

28 W. Tian, A. VahidMohammadi, M. S. Reid, Z. Wang, L. Ouyang, J. Erlandsson, T. Pettersson, L. Wagberg, M. Beidaghi and M. M. Hamedi, Advanced Materials, 2019, 31, 1902977.

29 S. Xu, Y. Dall'Agnese, J. Li, Y. Gogotsi and W. Han, Chem.-Eur. J., 2018, 24, 18556-18563.

30 C. Zhang, S. J. Kim, M. Ghidiu, M.-Q. Zhao, M. W. Barsoum, V. Nicolosi and Y. Gogotsi, Advanced Functional Materials, 2016, 26, 4143-4151.

31 A. Byeon, A. M. Glushenkov, B. Anasori, P. Urbankowski, J. Li, B. W. Byles, B. Blake, K. L. Van Aken, S. Kota, E. Pomerantseva, J. W. Lee, Y. Chen and Y. Gogotsi, J. Power Sources, 2016, 326, 686-694.

32 J. Luo, W. Zhang, H. Yuan, C. Jin, L. Zhang, H. Huang, C. Liang, Y. Xia, J. Zhang, Y. Gan and X. Tao, ACS Nano, 2016, 11, 2459-2469. 33 M. Naguib, J. Halim, J. Lu, K. M. Cook, L. Hultman, Y. Gogotsi and M. W. Barsoum, J. Mater. Chem. A, 2013, 135, 15966-15969.

34 J. Xiao, J. Wen, J. Zhao, X. Ma, H. Gao and X. Zhang, Electrochim. Acta, 2020, 337, 135803.

35 Q. Shan, X. Mu, M. Alhabeb, C. E. Shuck, D. Pang, X. Zhao, X.F. Chu, Y. Wei, F. Du, G. Chen, Y. Gogotsi, Y. Gao and Y. Dall'Agnese, Electrochemistry Communications, 2018, 96, 103-107.

36 A. K. Geim and I. V. Grigorieva, Nature, 2013, 499, 419-425.

37 K. S. Novoselov, A. Mishchenko, A. Carvalho and A. H. Castro Neto, Science, 2016, 353, aac9439.

38 E. Pomerantseva and Y. Gogotsi, Nat. Energy, 2017, 2, 17089.

39 Y. Liu, N. O. Weiss, X. Duan, H.-C. Cheng, Y. Huang and X. Duan, Nat. Rev. Mater., 2016, 1, 16042.

40 V. Augustyn, J.Come, M. A. Lowe, J. W. Kim, P. L. Taberna, S. H. Tolbert, H. D. Abruna, P. Simon and B. Dunn, Nature materials, 2013, 12, 518-522.

41 X. Mu, D. Wang, F. Du, G. Chen, C. Wang, Y. Wei, Y. Gogotsi, Y. Gao and Y. Dall'Agnese, Advanced Functional Materials, 2019, 29, 1902953.

42 M. Khazaei, A. Ranjbar, M. Arai, T. Sasaki and S. Yunoki, J. Mater. Chem. C, 2017, 5, 2488-2503 